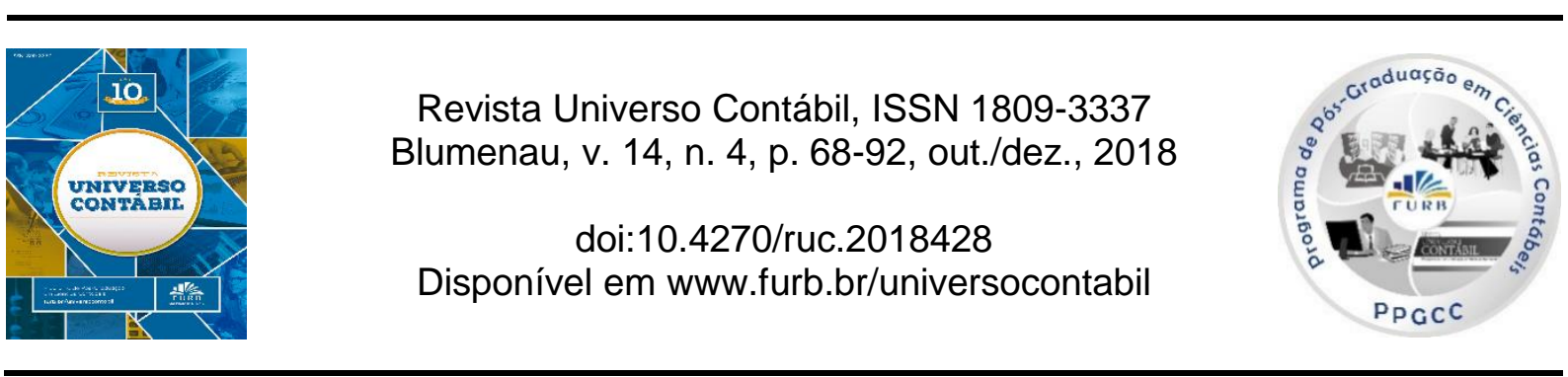

\title{
INVESTIMENTOS PÚBLICOS E FATORES POLÍTICOS NOS PEQUENOS MUNICÍPIOS BRASILEIROS: O QUE É RELEVANTE?
}

\author{
PUBLIC INVESTMENTS AND POLITICAL FACTORS IN SMALL BRAZILIAN \\ MUNICIPALITIES: WHAT IS RELEVANT?
}

\section{INVERSIONES PÚBLICAS Y FACTORES POLÍTICOS EN LOS PEQUEÑOS MUNICIPIOS BRASILEÑOS: ¿QUÉ ES RELEVANTE?}

\begin{abstract}
Willson Gerigk
Doutor em Políticas Públicas pela Universidade Federal do Paraná Professor do Departamento de Ciências Contábeis da Universidade Estadual do Centro-Oeste Endereço: PR $153 \mathrm{Km} 7$ - Riozinho CEP 84500-000 - Irati - PR - Brasil E-mail:wgerigk@unicentro.br Telefone: (42) 3421-3000

Flávio Ribeiro

Doutorando em Contabilidade pela Universidade Federal do Paraná Professor do Departamento de Ciências Contábeis da Universidade Estadual do Centro-Oeste Endereço: PR $153 \mathrm{Km} 7$ - Riozinho CEP 84500-000 - Irati - PR - Brasil E-mail: flavioribeiro@unicentro.br Telefone: (42) 3421-3000
\end{abstract}

\section{RESUMO}

A presente pesquisa estudou os municípios brasileiros com menos de cinco mil habitantes. $\mathrm{O}$ objetivo foi analisar a influência de variáveis políticas sobre os gastos com investimentos públicos realizados pelos municípios brasileiros com menos de cinco mil habitantes. As análises foram realizadas empregando-se a técnica de dados em painel pelo método de efeitos fixos. As variáveis explicativas referem-se aos seguintes fatores políticos: (i) ciclo político orçamentário; (ii) ideologia partidária; (iii) alinhamento político entre os pequenos municípios e os níveis superiores de governo; e (iv) competição política. A análise englobou os anos de 2001 a 2012 e a amostra inicial englobou 11.778 observações. Os resultados indicaram que os investimentos públicos foram influenciados pelos ciclos políticos orçamentários, tanto nas eleições estaduais/federais como nas municipais, entretanto, apresentaram maior aplicação de valores em anos de pleitos estaduais/federais. A ideologia partidária revelou que, para o conjunto de todos os pequenos municípios, os partidos de centro e de direita aplicaram mais recursos em

\footnotetext{
${ }^{1}$ Artigo recebido em 15/12/2017. Revisado por pares em 30/11/2018. Reformulado em 15/12/2018. Recomendado para publicação em 06/05/2019 por Marcia Zanievicz Silva. Publicado em 13/05/2019. Organização responsável pelo periódico: FURB.
} 
INVESTIMENTOS PÚBLICOS E FATORES POLÍTICOS NOS PEQUENOS MUNICÍPIOS BRASILEIROS: O QUE É RELEVANTE?

investimentos públicos que os partidos ideologicamente de esquerda. Entre as regiões, esse fato somente foi registrado no Sul. O alinhamento político, por meio de coligações indiretas, entre os pequenos governos locais e o governo federal e os estaduais, foi a forma de relação política que mais impactou os investimentos nos pequenos entes locais. Por fim, os investimentos públicos, nos municípios brasileiros com população inferior a cinco mil habitantes, não se mostraram suscetíveis à competição política.

Palavras-chave: Pequenos municípios brasileiros; Investimentos públicos; Fatores políticos.

\section{ABSTRACT}

The present study studied Brazilian municipalities with less than five thousand inhabitants. The objective was to analyze the influence of political variables on public investment expenditures made by Brazilian municipalities with less than five thousand inhabitants. The analyzes were performed using the panel data technique by the fixed effects method. The explanatory variables refer to the following political factors: (i) budget political cycle; (ii) party ideology; (iii) political alignment between small municipalities and upper levels of government; and (iv) political competition. The analysis covered the years 2001 to 2012 and the initial sample is composed of 11,778 observations. The results indicated that public investments were influenced by budgetary political cycles, both in state/federal and municipal elections, however, public investments were greater in the years of state and federal elections. Party ideology revealed that, for all small municipalities, central and right-wing parties applied more resources in public investments than left-wing ideological parties. Among the regions, this fact was only registered in the South. Political alignment through indirect coalitions between small local governments and the federal and state governments was the form of political relationship that most impacted investments in small local entities. Finally, public investments in Brazilian municipalities with a population of less than 5,000 inhabitants were not susceptible to political competition.

Keywords: Small Brazilian municipalities; Public investments; Political factors.

\section{RESUMEN}

La presente investigación estudió los municipios brasileños con menos de cinco mil habitantes. El objetivo fue analizar la influencia de variables políticas sobre los gastos con inversiones públicas realizadas por los municipios brasileños con menos de cinco mil habitantes. Los análisis se realizaron empleando la técnica de datos en panel por el método de efectos fijos. Las variables explicativas se refieren a los siguientes factores políticos: (i) ciclo político presupuestario; (ii) ideología partidista; (iii) alineamiento político entre los pequeños municipios y los niveles superiores de gobierno; y (iv) competencia política. El análisis abarcó los años 2001 a 2012 y la muestra inicial englobó 11.778 observaciones. Los resultados indicaron que las inversiones públicas fueron influenciadas por los ciclos políticos presupuestarios, tanto en las elecciones estatales / federales como en las municipales, sin embargo, presentaron mayor aplicación de valores en años de pleitos estaduales / federales. La ideología partidista reveló que, para el conjunto de todos los pequeños municipios, los partidos de centro y de derecha aplicaron más recursos en inversiones públicas que los partidos ideológicamente de izquierda. Entre las regiones, ese hecho sólo se registró en el Sur.La alineación política por medio de coaliciones indirectas, entre los pequeños gobiernos locales y el gobierno federal y los estatales, fue la forma de relación política que más impactó las inversiones en los pequeños entes locales. Por último, las inversiones públicas, en los municipios brasileños con población inferior a cinco mil habitantes, no se mostraron susceptibles a la competencia política. 
Palabras clave: Pequeños municipios brasileños; Inversiones públicas; Factores políticos.

\section{INTRODUÇÃO}

Politicamente, os investimentos públicos são altamente visíveis à população e, consequentemente, motivam os policy makers a empreenderem esforços com o objetivo de aumentar a aplicação de recursos nessa modalidade de gasto público, tanto na esfera municipal como federal e estadual. Tal motivação ocorre devido às características que os investimentos possuem, como: os benefícios que geram à população, maior adaptabilidade ao calendário eleitoral, podem ser custeados por diferentes fontes de recursos e por estarem mais sujeitos à arbitrariedade do gestor, em razão de seu caráter particularista (ORAIR; GOUVÊA; LEAL, 2014).

Bezerra (2001), ao abordar a relação entre obras públicas e política, destaca que é interessante observar como essas obras incorporam e expressam certas propriedades opostas. Por um lado, produzem benefícios coletivos, ao atenderem interesses de uma multiplicidade de pessoas, estão mais associadas às exigências de uma aplicação democrática dos recursos públicos. Por outro, quando se acompanha o processo de realização e divulgação de grande parte dessas obras, percebe-se que há todo um esforço de singularização dirigido para associálas a certa administração e/ou grupo político. Ao invés de serem apresentadas como um ato impessoal do poder público, como um retorno dos impostos pagos, as obras são apresentadas como benefícios proporcionados por políticos, em particular.

Assim, investir na promoção de benefícios coletivos, como obras públicas, tem sido historicamente uma forma de acumular prestígio político. As obras públicas estão associadas, portanto, à reputação do político e a uma concepção específica sobre a política (BEZERRA, 2001).

Evidências empíricas sobre a importância política dos gastos com investimentos públicos na esfera municipal são encontradas em Leite (2010), que investigou a responsabilização dos governos municipais (agentes) frente aos cidadãos locais (beneficiários das políticas públicas) e ao governo federal (transferidor dos recursos) em relação às políticas públicas da área de assistência social, educação e saúde, entre 1997 e 2004 . Um dos achados foi que a taxa de investimentos (como a realização de obras) tem maior impacto eleitoral que a melhoria dos serviços públicos nas áreas de saúde e de educação.

O estudo de Arvate e Vieira (2008) sobre a influência das transferências voluntárias oriundas da União e dos estados acerca das receitas e das despesas dos municípios brasileiros, entre 1996 a 2004, revelou que o aumento das transferências voluntárias se mostrou relevante para explicar o incremento dos gastos com investimentos públicos locais.

Pesquisas brasileiras mais específicas, como a de Sakurai e Gremaud (2007), que analisaram os municípios do estado de São Paulo, entre 1989 e 2001, para determinar os efeitos do calendário eleitoral e da vinculação partidária dos prefeitos sobre as despesas municipais. Os resultados, em relação aos investimentos municipais, indicaram que o calendário eleitoral não foi influente e que os prefeitos pertencentes ao Partido da Frente Liberal - PFL (atual Democratas - DEM) foram os que mais aplicaram recursos em despesas com investimentos locais.

Nessa mesma linha, Queiroz (2015) investigou o comportamento das despesas municipais e seu relacionamento com os períodos eleitorais. A amostra compreendeu os municípios brasileiros nos anos de 2004 (4.025), 2008 (4.389) e 2012 (4.433). Os resultados demonstram que, de modo geral, os entes cujos partidos foram reconduzidos aplicam percentuais mais elevados da despesa orçamentária em gastos finalísticos, reduzindo as despesas administrativas.

Outro estudo, com essa temática, é de Rodrigues (2010) que pesquisou os municípios do estado de Santa Catarina, com mais de 50 mil habitantes, entre 2005 a 2008, como o objetivo 
de identificar a relação entre ideologia partidária e os gastos com investimentos públicos. A pesquisa evidenciou uma tendência relativamente homogênea de variação dos gastos entre os grupos ideológicos, que os investimentos públicos locais são influenciados por fatores orçamentários relativos às áreas de educação e saúde e seguem o calendário eleitoral, ou seja, o volume de gastos é intensificado no último ano do mandato, demonstrando preocupação com o resultado das eleições.

As aplicações de recursos realizadas pelos pequenos municípios brasileiros, em investimentos públicos, exercem forte apelo político no âmbito local e exigem, tanto ações administrativas (programação orçamentária, projetos, licitações etc.) como políticas (aprovação legislativa, captação de recursos, período de realização, entre ouros) dos gestores para serem efetivadas.

As pesquisas que abordam as aplicações de recursos, por parte dos municípios, em investimentos públicos, trataram dos efeitos dos períodos eleitorais e da ideologia partidária do prefeito e analisam os municípios sem considerar seu porte populacional, exceção feita a Rodrigues (2010). Para tratar essa questão, da homogeneidade da amostra, nesta pesquisa, são analisados os municípios brasileiros com menos de 5 mil habitantes que, via de regra, veem sendo estudados junto com os de maior população. Também, são abordados outros fatores políticos além os efeitos do calendário eleitoral e da ideologia política, como as formas de alinhamento político dos entes locais e os superiores (União e estados) e a competição política. Ou seja, a pesquisa avança sobre um grupo de entes locais poucos estudados e amplia, em uma mesma análise, o conjunto de variáveis que podem influenciar os gastos em investimentos públicos locais. Nesse sentido, a pergunta que a pesquisa pretende responder é: quais fatores do sistema político brasileiro influenciaram os gastos com investimentos públicos dos municípios com menos de cinco mil habitantes?

O objetivo da presente pesquisa é analisar a influência de variáveis políticas sobre os gastos com investimentos públicos realizados pelos municípios brasileiros com menos de cinco mil habitantes, no período de 2001 a 2012. Segundo Sakurai (2009), é importante considerar que, após a Constituição Federal de 1988, e devido à proximidade dos indivíduos, em relação ao poder local, quando comparada com o estadual e o federal, as demandas da sociedade por serviços públicos recaiam, principalmente, sobre as administrações municipais.

Pressupondo que tais demandas se acentuam, à medida que o tamanho dos municípios diminui, a pesquisa segrega as variáveis políticas capazes de exercer influência em (i) períodos eleitorais, (ii) ideologia partidária, (iii) formas de vinculação política entre os governos locais e os entes públicos superiores (União e Estados) e (iv) competição política sobre os gastos com investimentos públicos nos municípios brasileiros com menos de cinco mil habitantes, no período de 2001 a 2012.

O estudo ajuda a preencher lacunas relacionadas ao entendimento de aspectos comportamentais que se refletem nos investimentos públicos. Especificamente, quando se consideram os municípios brasileiros com menos de cinco mil habitantes, foram encontrados poucos estudos que tratassem do tema, o que apresenta uma possibilidade profícua de inserir esta temática na discussão teórica nessa área do conhecimento e, consequentemente, na verificação empírica entre os atores no campo do ensino e pesquisa em contabilidade pública. Ademais, os municípios com menos de cinco mil habitantes necessitam constantemente de recursos oriundos de repasses da união e dos estados para se organizar e lidar com suas necessidades.

A segunda seção aborda a revisão da literatura e o desenvolvimento das hipóteses. $\mathrm{Na}$ sequência, a metodologia da pesquisa é explicitada. Os efeitos das variáveis políticas são descritos na quinta seção. Na conclusão, os achados da pesquisa são evidenciados. 


\section{REVISÃO DA LITERATURA E DESENVOLVIMENTO DAS HIPÓTESES}

Os gastos com investimentos públicos frequentemente são utilizados como uma variável importante nas pesquisas que enfatizam os gastos públicos e seus efeitos políticos como, por exemplo, Drazen e Eslava (2005), Veiga e Veiga (2007), Vieira e Arvate (2008), Rodrigues (2010), Leite (2010), Borges (2010), Videira e Mattos (2011), Orair, Gouvêa e Leal (2014) e Reis e Santana (2015). Entretanto, os estudos que abordam essa relação apresentam resultados diferentes quanto aos efeitos de variáveis políticas sobre os gastos com investimentos públicos. Drazen e Eslava (2005) estudaram os impactos dos períodos eleitorais sobre os investimentos públicos dos municípios colombianos, no período de 1992 a 2000, destacaram que os governantes, nos períodos pré-eleitorais, aumentaram as despesas com itens considerados atraentes para os eleitores, como construções de rodovias e redes de abastecimento de água, evidenciando, segunda a literatura do ciclo político orçamentário, a intenção de influenciar o eleitorado.

O estudo de Veiga e Veiga (2007), com os municípios portugueses, no período de 1979 a 2000, revelou que os investimentos públicos locais cresceram em períodos pré-eleitorais, especialmente em gastos que são altamente visíveis ao eleitorado, como viadutos, ruas e estradas rurais, sugerindo um esforço para sinalizar competência e melhorar as chances de reeleição. Os resultados indicaram, também, que prefeitos pertencentes à ideologia de esquerda tendem aplicar mais recursos em gastos com investimentos públicos nos períodos eleitorais do que os de direita. No entanto, tais gastos independem se o partido do prefeito tem maioria na assembleia municipal ou se o titular governou por mais de um mandato.

Quanto à influência das transferências voluntárias, oriundas da União e dos estados sobre as receitas e as despesas nos municípios brasileiros, Vieira e Arvate (2008) concluíram que o aumento das transferências voluntárias se mostrou relevante para explicar o incremento dos gastos com investimentos públicos locais.

No que se refere à relação entre a ideologia partidária e os gastos com investimentos públicos, Rodrigues (2010) pesquisou os municípios, do estado de Santa Catarina, com mais de 50 mil habitantes, no mandato de 2005-2008. Os resultados indicaram uma tendência relativamente homogênea de variação dos gastos entre os grupos ideológicos e que os investimentos públicos são influenciados por fatores orçamentários relativos às áreas de educação e saúde e alteram-se com o calendário eleitoral, ou seja, o volume de gastos é intensificado no último ano do mandato, demonstrando preocupação com o resultado das eleições. No estudo de Sakurai e Gremaud (2007), com os municípios do estado de São Paulo, entre os anos de 1989 e 2001, os investimentos municipais não foram influenciados pelo calendário eleitoral.

Baseando-se na teoria da agência, Leite (2010) investigou a responsabilização dos governos locais brasileiros (agentes) frente aos cidadãos locais (beneficiários das políticas públicas) e ao governo federal (transferidor dos recursos) em relação às políticas públicas da área de assistência social, educação e saúde, entre os anos de 1997 e 2004. Um dos achados foi que a taxa de investimentos (como a realização de obras) tem maior impacto eleitoral que a melhoria dos serviços públicos de saúde e educação.

Objetivando verificar os efeitos das receitas originárias de royalties petrolíferos sobre os investimentos locais, Reis e Santana (2015) investigaram 798 municípios brasileiros, no período de 1999 a 2011. Os resultados mostraram que os municípios mais dependentes quanto aos royalties elevaram suas despesas de capital quando ocorreu aumento dessa fonte de receita municipal, evidenciando a importância que tais repasses financeiros têm sobre o aumento dos investimentos municipais.

Os trabalhos consultados não são conclusivos sobre os efeitos dos aspectos do sistema político sobre os investimentos públicos locais. Diante disso, o presente estudo analisa a 
INVESTIMENTOS PÚBLICOS E FATORES POLÍTICOS NOS PEQUENOS MUNICÍPIOS BRASILEIROS: O QUE É RELEVANTE?

influência de variáveis políticas sobre os gastos com investimentos públicos realizados pelos municípios brasileiros com menos de cinco mil habitantes, no período de 2001 a 2012.

\subsection{Ciclo político orçamentário}

A teoria do ciclo político orçamentário, proposta por Rogoff e Sibert (1988) e Rogoff (1990), baseada no estudo de Nordhaus (1975), defende que os partidos governantes, independentemente da ideologia política, manipulam seus gastos orçamentários para políticas públicas altamente visíveis ao eleitorado, assumindo que os eleitores e os políticos são agentes racionais e maximizadores de utilidade. A tese geral é que quando os períodos eleitorais são conhecidos antecipadamente, os governantes tenderiam a tomar decisões, em especial de natureza orçamentária, para colocar em evidência suas gestões junto aos eleitores. A existência de informação incompleta proporciona incentivos para os governantes distorcerem a política fiscal pré-eleitoral, para aumentar a probabilidade de êxito nas eleições. Ressaltando que o modelo proposto contempla um comportamento sub ótimo dos eleitores devido à assimetria informacional, visto que, se os agentes são racionais suas expectativas também devem ser. Com isso, os eleitores internalizariam o comportamento dos políticos no poder.

Analisando a ocorrência de ciclo político orçamentário em países desenvolvidos e em desenvolvimento, no período de 1975 a 1995. Shi e Svensson (2006) concluem que o ciclo político orçamentário é um fenômeno universal. Em geral, os gastos aumentam e as receitas diminuem em anos eleitorais, resultando em maior déficit fiscal. Além disso, quando o calendário eleitoral é pré-determinado, os níveis de ocorrência do ciclo político orçamentário são mais elevados nos países em desenvolvimento do que nos países desenvolvidos.

Entretanto, Brender e Drazen (2004) afirmam que a ocorrência de ciclos orçamentários eleitorais é um fenômeno mais observado em países com "democracias novas" do que nos países com "democracias estabilizadas". Analisando países com essas características, entre 1960 a 2001, sugerem que o aumento da experiência eleitoral e da compreensão por parte dos eleitores sobre as informações orçamentárias podem restringir as manipulações efetivadas pelos governantes com objetivos eleitorais.

Os estudos internacionais têm confirmado a ocorrência de ciclos políticos orçamentários em municípios. Pettersson-Lidbom (2003), tratando de municípios suecos. Drazen e Eslava (2005) analisaram os entes locais colombianos. Veiga e Veiga (2007), em pesquisa com entes públicos locais portugueses. Nessa mesma linha de pesquisa, o estudo de Sakurai (2009), que englobou quase a totalidade dos municípios brasileiros de 1990 a 2005, verificou que certas despesas municipais são influenciadas em razão de interesses eleitorais dos prefeitos municipais, ou seja, aumentaram em períodos eleitorais.

Levando-se em consideração $(i)$ que, no Brasil, durante o período de um mandato municipal, ocorrem tanto eleições estaduais e federais como locais; (ii) que em ambos os casos o calendário eleitoral é pré-definido e institucionalizado e (iii) que diversos estudos nacionais indicaram a ocorrência de ciclos políticos orçamentários tanto em nível estadual como municipal (ARVATE; AVELINO; LUCINDA, 2008; ARVATE; VIEIRA, 2008; BITTENCOURT, 2002; COSSIO, 2001; NAKAGUMA; BENDER, 2010; OLIVEIRA; CARVALHO, 2009; SAKURAI, 2009), presume-se que esses efeitos também sejam encontrados nos municípios com menos de cinco mil habitantes. Assim, a primeira hipótese da pesquisa refere-se à ocorrência ou não de ciclos políticos orçamentários nos pequenos municípios.

Hipótese 1: Os gastos com investimentos públicos, nos pequenos municípios brasileiros, aumentam nos períodos de eleições. 


\subsection{Ideologia política}

A ideologia partidária é empregada nas análises sobre políticas públicas com o objetivo de detectar possíveis diferenças em relação às suas implementações e/ou desenvolvimentos, em razão da orientação ideológica dos partidos governantes. A classificação ideológica, normalmente empregada nessas pesquisas, leva em conta a forma pela qual os governos intervêm na economia.

Para Zucco Jr, (2011), esquerda e direita ainda estão claramente associadas a maior e menor intervenção do Estado na economia. Os partidos de esquerda tendem a preferir uma economia com estado dominante a qualquer outro tipo de arranjo; os de direita seriam caracterizados por preferirem um modelo de governo menos intervencionais, com características voltadas ao mercado e os de centro defenderiam um modelo de equilíbrio entre Estado e mercado.

Em relação às políticas públicas, Cavalcante (2012) argumenta que os partidos de esquerda apresentariam uma postura mais intervencionista e um desempenho mais ativo, sendo mais favoráveis ao aumento da tributação e de políticas sociais redistributivas. Os de direita exibiriam uma postura contrária a essa quando no governo.

Ao abordarem a ideologia e os gastos sociais, Tarouco e Madeira (2013a, p.150), destacam que os gastos sociais, além de afetarem os resultados macroeconômicos, são medidas redistributivas e, portanto, políticas preferidas por governos de esquerda, enquanto políticas de ajuste fiscais seriam preferidas por governos de centro e de direita. O pressuposto dessa literatura é que tais preferências decorrem dos vínculos dos partidos com classes sociais: partidos de esquerda representam classes trabalhadoras e partidos de direita são identificados com proprietários e grupos sociais privilegiados.

As pesquisas brasileiras que avaliaram as diferenças de resultado entre os partidos governantes, com ideologias classificadas no eixo esquerda-centro-direita, apresentaram resultados distintos e contraditórios, dependendo do nível de governo e da política pública analisada, a exemplo de Rodrigues (2007), Sakurai (2009), Oliveira e Carvalho (2009), Cavalcante (2012).

Quanto à hipótese de que partidos políticos, de diferentes concepções ideológicas, aplicariam de forma distinta os recursos na esfera municipal, Rodrigues (2007), analisando os municípios do estado de Santa Catarina, entre 1993 a 2000, concluiu não ser possível afirmar que existem diferenças na aplicação dos recursos municipais entre os partidos de esquerda quando comparados com os de centro e os de direita. E que as diferenças percebidas nos volumes de gastos foram cíclicas e independeram da concepção ideológica do partido político que estava no governo local.

O estudo de Sakurai (2009), com os municípios brasileiros, revelou que os partidos de esquerda e de direita destinaram mais recursos em saúde e saneamento e menos em habitaçãourbanismo e educação que os de centro. Entretanto, o de Oliveira e Carvalho (2009), com os municípios do estado do Rio de Janeiro de 1998 a 2006, indicou que os partidos políticos classificados como de esquerda gastaram mais nas funções de governo agricultura, habitação e urbanismo que os partidos de direita.

Cavalcante (2012) analisou o impacto de variáveis relativas ao sistema político sobre os gastos sociais municipais: educação, saúde, assistência social, saneamento e habitação, entre 1996 a 2010. Os resultados em relação à ideologia partidária seguem a literatura, ou seja, partidos de esquerda arrecadaram mais impostos e apresentaram melhores resultados nas áreas sociais analisadas, confirmando a existência de diferenças ideológicas na aplicação de recursos entre os municípios brasileiros.

Para Tarouco e Madeira (2013b), as diferenças ideológicas continuam sendo utilizadas como variável independente para explicar desde a coerência de coligações até a execução de políticas públicas pelos governos. A principal controvérsia em relação à análise da ideologia 
partidária em políticas públicas, segundo Sátyro (2008), engloba o problema da existência ou não de resultados discrepantes em razão das diferenças ideológicas entre partidos que estão governando.

Na presente pesquisa, assume-se que os partidos políticos classificados na ideologia de esquerda (usados como referência) tendem a apresentar estruturas de governos maiores e mais ativas, bem como maior preocupação com as políticas sociais do que os partidos políticos de centro e de direita. Diante disso, a hipótese testada é a seguinte:

Hipótese 2: Gestões municipais realizadas por partidos de esquerda tendem a destinar maior volume de recursos em gastos com investimentos públicos do que as de partidos de centro e de direita.

\subsection{Alinhamentos políticos entre os governos locais e os entes públicos superiores}

As análises, envolvendo o alinhamento político-partidário entre os pequenos governos municipais e os entes públicos superiores (União e estados), buscam identificar se os vínculos partidários entre os poderes executivos de diferentes níveis de governo implicam melhores condições para o desenvolvimento de políticas públicas locais.

Arvate, Avelino e Lucinda (2008) argumentam que o vínculo partidário entre os chefes dos poderes executivos pode levar a certos "privilégios políticos", em especial, do federal para os estaduais e municipais. Segundo Cavalcante (2012), pesquisas envolvendo as transferências voluntárias da União aos estados e municípios buscam verificar a existência de "um canal de solidariedade partidária” entre os níveis de governo.

Arretche e Rodden (2004) realizaram estudo nesse sentido, no período de 1991 a 2000, testando, entre outras hipóteses, se as localidades controladas pelos partidos ou pelos Governadores pertencentes à coalizão do Presidente da República seriam beneficiadas pelas transferências intergovernamentais sujeitas à autoridade do Presidente, ou seja, transferências com algum grau de discricionariedade. Os resultados sugerem que os parlamentares que pertenciam à coalizão do Presidente aumentaram exponencialmente suas chances de obter recursos voluntários para seus estados ou municípios de origem.

No âmbito municipal, Ferreira e Bugarin (2007), em pesquisa englobando 2.090 municípios, nos anos de 1999 a 2004, concluíram que existem evidências empíricas de que parte das receitas de transferências voluntárias recebidas pelos governos municipais é politicamente motivada, isto é, os municípios em que Prefeito pertencia à coligação que elegeu o Governador do estado ou vinculado ao mesmo partido do Presidente da República receberam mais recursos voluntários, do que aqueles que não se encontravam nesta mesma posição política.

O estudo de Vieira e Arvate (2008), entre 1996 a 2004, com 4.023 municípios, confirmou que os repasses de transferências voluntárias aumentaram nos períodos eleitorais, sendo relevante para explicar o incremento dos gastos sociais e com investimentos públicos nos municípios alinhados politicamente com o Presidente e o Governador do estado, confirmando o viés político das transferências voluntárias.

A presente pesquisa considera que o alinhamento político entre os pequenos governos municipais e os dos entes públicos superiores (União e Estados) podem impactar os resultados financeiros dos municípios e propiciar melhores condições para as finanças locais, neste sentido a hipótese testada é:

Hipótese 3: Os governos municipais alinhados politicamente com o governo federal elou estadual tendem a ter níveis maiores de gastos em investimentos públicos. 


\subsection{Competição política}

A competição política, no âmbito dos municípios brasileiros com menos de cinco mil habitantes, é o último fator analisado. Segundo Sátyro (2008), quando existe um alto nível de competição eleitoral e, por isso, influência política efetiva dos pobres (direito ao voto), os políticos têm fortes incentivos para aumentar os gastos em políticas sociais. $\mathrm{O}$ argumento implícito é de que ambientes com competição eleitoral apresentam níveis de incerteza para as elites partidárias, isto promove maior responsabilidade destas em relação às necessidades dos cidadãos.

Chhibber e Nooruddin (2004), em pesquisa com os estados indianos, no período de 1967 a 1997, revelaram que nos sistemas em que a disputa eleitoral é mais concentrada, como no bipartidário, existe a necessidade de coalizões mais amplas (menor concorrência política), resultando na provisão de bens públicos voltados às necessidades gerais da população, como energia elétrica e água potável. Enquanto isso, nos sistemas em que a concorrência eleitoral é mais dispersa (maior disputa política), como nos multipartidários, os partidos têm incentivos para desenvolver ações para grupos específicos de eleitores, resultando em menor provisão de bens públicos de caráter universal. Isto é, quanto maior o nível de competição política para aos cargos eletivos, menores os incentivos para que os recursos sejam aplicados em bens públicos.

Quanto aos impactos da competição política junto às políticas sociais dos estados brasileiros, Sátyro (2008) desvendou um carácter frágil e marginal desse fator político na provisão de políticas sociais na esfera estadual, após a redemocratização. A pesquisa indicou que a competição política não exerceu influência sobre as políticas sociais.

Abordando os efeitos da competição eleitoral na esfera municipal, Coêlho (2010), analisou os municípios paulistas entre 1995 a 2001, os resultados indicaram que a criação de políticas públicas locais de transferência de renda ocorreu em maior proporção nos municípios com competição eleitoral alta e que a probabilidade de adesão ao programa federal de transferência de renda foi maior em municípios com ambientes políticos menos competitivos.

Cavalcante (2013) estudou os municípios brasileiros com a finalidade de verificar se o grau de competição eleitoral nos pleitos municipais exerceria influência sobre a atuação dos Prefeitos, entre 2002 a 2009. Os resultados surpreenderam ao demonstrarem, mesmo diante do fato de o país viver em uma democracia com eleições frequentes e multipartidarismo, que a ameaça eleitoral não exerceu impacto relevante sobre o desempenho dos Prefeitos, em relação aos gastos realizados nas áreas de assistência social, educação e saúde.

A última hipótese, que a pesquisa avalia, diz respeito à competição política no âmbito dos municípios brasileiros com menos de 5 mil habitantes. Assume-se que, quanto maior a competição política, no âmbito municipal, maiores os gastos com as políticas públicas que beneficiam o maior número de cidadãos, isto é, com as políticas sociais. Com isso, a hipótese indicada é:

Hipótese 4: Quanto maior for o nível de competição política nas eleições municipais menor a tendência de que os municípios aumentem os gastos com investimentos públicos.

\section{METODOLOGIA DA PESQUISA}

A abordagem é quantitativa, com emprego de análise multivariada de dados em painel. Segundo Fávero et al. (2009), essa técnica combina a abordagem cross-sectional (que estuda o comportamento das variáveis para as observações da amostra com o tempo fixo: dia, mês ou ano) e de séries temporais (que estuda a evolução das variáveis de uma observação durante determinado período de tempo). Assim, a análise de dados em painel permite monitorar as variáveis de diversas observações ao longo de vários períodos de tempo. 
Como nem todos os municípios possuíam dados para compor as variáveis em todos os anos da série tem-se um painel desbalanceado. O método definido para ser utilizado nas análises de dados em painel, após a realização dos testes estatísticos indicados, foi o de efeitos fixos.

As variáveis explicativas empregadas na pesquisa mantêm relação com (i) o calendário eleitoral, tanto municipal como o federal e o estadual, (ii) a ideologia partidária, (iii) as formas de alinhamento político entre os governos municipais e os governos estadual e federal e (iv) a competição política. Também, são usadas variáveis de controle relacionadas a aspectos socioeconômicos dos pequenos municípios. O Quadro 1 apresenta a matriz com a relação esperada entre os gastos com investimento públicos locais e as variáveis independentes.

Quadro 1: Matriz com as variáveis explicativas, variáveis de controle e a relação esperada com os investimentos públicos municipais

\begin{tabular}{|c|c|c|c|}
\hline \multicolumn{2}{|r|}{ Variáveis } & \multirow{2}{*}{$\begin{array}{l}\text { Investimentos } \\
\text { Públicos } \\
(+)\end{array}$} & \\
\hline \multirow{4}{*}{$\begin{array}{l}\text { Variáveis } \\
\text { Explicativas } \\
\text { Políticas }\end{array}$} & $\begin{array}{l}\text { Ano Eleição Federal } \\
\text { Ano Eleição Municipal }\end{array}$ & & $\begin{array}{l}\text { Cossio (2001), Nakaguma (2006), } \\
\text { Sakurai e Gremaud (2007), Arvate, } \\
\text { Avelino e Lucinda (2008), Sakurai } \\
\text { (2009), Oliveira e Carvalho (2009), } \\
\text { Leite (2010), Videira e Mattos } \\
\text { (2011), Cavalcante (2012). }\end{array}$ \\
\hline & $\begin{array}{l}\text { Ideologia Partidária - Centro } \\
\text { Ideologia Partidária - Direita }\end{array}$ & $\begin{array}{l}(-) \\
(-)\end{array}$ & $\begin{array}{l}\text { Sátyro (2008), Sakurai (2009), } \\
\text { Oliveira e Carvalho (2009), } \\
\text { Cavalcante }(2012,2013) .\end{array}$ \\
\hline & $\begin{array}{l}\text { Relação Partidária Presidente } \\
\text { Relação Partidária Governador } \\
\text { Coligação Direta Presidente } \\
\text { Coligação Direta Governador } \\
\text { Coligação Indireta Presidente } \\
\text { Coligação Indireta Governador }\end{array}$ & $\begin{array}{l}(+) \\
(+) \\
(+) \\
(+) \\
(+) \\
(+)\end{array}$ & $\begin{array}{l}\text { Cossio (2001), Bittencourt (2002), } \\
\text { Nakaguma (2006), Arvate, Avelino } \\
\text { e Lucinda (2008), Sakurai (2009), } \\
\text { Oliveira e Carvalho (2009),Videira e } \\
\text { Mattos (2011), Cavalcante (2012). }\end{array}$ \\
\hline & $\begin{array}{l}\text { Número Efetivo de Partidos (NEP) - } \\
\text { Executivo Municipal } \\
\text { Número Efetivo de Partidos (NEP) - } \\
\text { Legislativo Municipal }\end{array}$ & $\begin{array}{l}(-) \\
(-)\end{array}$ & $\begin{array}{l}\text { Bittencourt (2002), Sátyro (2008), } \\
\text { Cavalcante }(2012,2013) .\end{array}$ \\
\hline $\begin{array}{l}\text { Variáveis de } \\
\text { Controle }\end{array}$ & $\begin{array}{l}\text { População Total (Logaritmo Natural) } \\
\text { População Jovem - \% (<15 anos de } \\
\text { idade) } \\
\text { População Idosa - \% (> } 60 \text { anos de } \\
\text { idade) } \\
\text { PIB municipal per capita }\end{array}$ & $\begin{array}{l}(+) \\
(+) \\
(+) \\
(+)\end{array}$ & $\begin{array}{l}\text { Sakurai e Gremaud (2007), Arvate, } \\
\text { Avelino e Lucinda (2008), Sakurai } \\
\text { (2009), Videira e Mattos (2011), } \\
\text { Cavalcante }(2012,2013) .\end{array}$ \\
\hline
\end{tabular}

Fonte: Os autores (2018).

Os efeitos dos anos eleitorais sobre as variáveis explicadas são avaliados utilizando as eleições municipais (2004, 2008 e 2012) e as eleições federais/estaduais (2002, 2006 e 2010), representadas por variáveis dummies. Espera-se que os gestores dos pequenos municípios priorizem a aplicação dos recursos municipais em investimentos públicos. Com isso, aguardase que a relação entre esses períodos e tais gastos seja positiva.

A segmentação dos pequenos municípios por ideologia partidária visa detectar possíveis diferenças em relação aos gastos públicos, levando em conta a forma de atuação dos governos em relação às políticas públicas desenvolvidas por meio da execução do orçamento público. Acredita-se que os gestores locais vinculados aos partidos de esquerda (usados como referência nas análises) apliquem mais recursos em investimentos públicos que os de centro e de direita. Com isso, o sugerido é que estes apresentem relação negativa com os investimentos públicos quando comparados com as aplicações realizadas pelos partidos de esquerda. 
Para determinar possíveis diferenças entre as ideologias políticas dos administradores municipais (esquerda, centro e direita) e os tipos de gastos públicos, utilizamos os partidos políticos de esquerda como referências nas análises. A representação deu-se por meio de variáveis dummies. Os partidos de esquerda receberam valor zero (0) e os de centro e de direita um (1).

A classificação dos partidos dos prefeitos dos pequenos municípios nas ideologias de esquerda, centro e direita baseia-se em Fernandes (1995), Coppedge (1997), Mainwaring et al. (2000), Rodrigues (2002) e Zucco Jr. (2011). Com base nesses autores, PPB/PP, PTB, PSL, PST, PSC, PL/PR, PFL/DEM, PSDC, PTC, PSD, PRP e Prona são classificados como partidos de direita; PMDB, PSDB e PPS como de centro; e PDT, PT, PMN, PSB, PV e PC do B são classificados como de esquerda. A partir dessas referências não foi possível classificar ideologicamente cinco partidos: PRB, PTN, PRTB, PHS e PT do B, sendo excluídos das análises. Esse grupo de partidos, inclassificável na literatura utilizada nesta pesquisa, totalizou 74 observações, sendo 6 no Norte; 18 no Nordeste; 20 no Centro-Oeste; 26 no Sudeste e 4 no Sul.

O alinhamento político entre os Prefeitos dos pequenos municípios e o Presidente da República foi estabelecido por meio de três variáveis dummies. A primeira indica se ambos eram do mesmo partido político (relação partidária presidente); a segunda definiu se o partido do Presidente fez parte da coligação que elegeu o Prefeito (coligação direta presidente) e a terceira estabeleceu se pelo menos um dos partidos políticos da coligação do Presidente fez parte da coligação municipal que elegeu o Prefeito, excluído o partido do Presidente (coligação indireta presidente).

O mesmo procedimento foi empregado em relação às vinculações políticas dos pequenos municípios com o governo do seu estado: relação partidária governador, coligação direta governador e coligação indireta governador.

Aguarda-se que os alinhamentos políticos entre os governos dos pequenos municípios e os dos governos federal e estadual contribuam para o aumento dos gastos com investimentos públicos nos pequenos municípios (relações positivas nos modelos de regressão), decorrentes de possíveis direcionamentos de recursos federais e estaduais, em especial sob a forma de transferências voluntárias, para a realização de obras ou aquisição de materiais permanentes, aos pequenos municípios aliados politicamente.

A competição política é representada por: (i) o número efetivo de partidos (NEP) do Executivo municipal e (ii) o número efetivo de partidos (NEP) do Legislativo municipal. Segundo Chhibber e Nooruddin (2004) e Borges (2010), quanto maior o nível de competição para os cargos políticos, menores os incentivos para que os gastos públicos sejam direcionados à provisão de bens públicos. Os gestores se comportariam mantendo sua base de apoio político, provendo gastos para atender as necessidades específicas de determinados grupos, em especial os aliados, tornando mais privados os gastos públicos, como por exemplo, a provisão de cargos de livre exoneração.

Assim, em relação aos pequenos municípios espera-se que, quanto maior a competição política, menor o volume gasto com investimentos municipais, evidenciando relação negativa entre as variáveis representativas da competição política local e os gastos em análise.

Quanto às relações entre as variáveis de controle com os gastos dos pequenos municípios em investimentos públicos, esperam-se os seguintes resultados:

(i) População total: quanto maior a população, maiores as necessidades por serviços públicos, assim, maiores seriam os recursos aplicados em investimentos públicos.

(ii) População jovem e a idosa: quanto maiores, tanto maiores são as necessidades por estruturas físicas e equipamentos para a prestação de serviços públicos. Espera-se, portanto, relação positiva com os investimentos públicos. 
(iii) PIB municipal per capita: quanto maior a atividade econômica local, melhores as condições econômicas à tributação própria e para os repasses de receitas vinculadas às atividades econômicas. Com isso, aguarda-se relação positiva entre o PIB local e os gastos com investimentos públicos nos pequenos municípios brasileiros.

Os modelos de regressão apresentaram autocorrelação residual. Para tratar essa questão empregou-se o processo autorregressivo de primeira ordem (AR1), que assume a existência e corrige a autocorrelação residualmediante a inclusão como variável explicativa da dependente defasada $\left(\mathrm{Y}_{\text {it-1 }}\right)$. Com isso, os modelos analisados seguem a formalização da Equação 1:

$\mathrm{Y}_{\text {it }}=\beta_{0 \mathrm{it}}+\beta_{1}\left(\right.$ Dummy_Ano Eleição Federal/Estadual $\left._{i t}\right)+\beta_{2}($ Dummy_Ano Eleição

Municipal $\left._{i t}\right)+\beta_{3}\left(\right.$ Dummy_Ideologia de Centroit $\left._{i}\right)+\beta_{4}\left(\right.$ Dummy_Ideologia de Direita $\left._{i t}\right)+$

$\beta_{5}$ (Dummy_Relação Partidária Presidente $)+\beta_{6}$ (Dummy_Coligação Direta Presidente ${ }_{i t}$ )

$+\beta_{7}\left(\right.$ Dummy_Coligação Indireta Presidente $\left._{i t}\right)+\beta_{8}($ Dummy_Relação Partidária

Governador $\left._{i t}\right)+\beta_{9}\left(\right.$ Dummy_Coligação Direta Governador $\left._{i t}\right)+\beta_{10}\left(\right.$ Dummy_Coligação $_{-}$

Indireta Governador $\left.{ }_{i t}\right)+\beta_{11}\left(\right.$ NEP Executivo Municipal $\left.{ }_{i t}\right)+\beta_{12}$ (NEP Legislativo

Municipal $\left._{\text {it }}\right)+\beta_{13}\left(\right.$ População Total - Logaritmo Natural $\left._{\text {it }}\right)+\beta_{14}\left(\right.$ População Jovem-\% $\left._{\text {it }}\right)$

$+\beta_{15}\left(\right.$ População Idosa-\% $\left.{ }_{\text {it }}\right)+\beta_{16}\left(\right.$ PIB Municipal per capita $\left.{ }_{\mathrm{it}}\right)+\alpha_{\mathrm{i}}+\mu_{\mathrm{it}}$

Onde:

$\mathrm{Y}=$ variável dependente

$\beta=$ parâmetro associado ao i-ésimo município no t-ésimo ano ou ao intercepto

$\alpha=$ efeito não observado de cada município

$\mu=$ termo de erro

$\mathrm{i}=$ representa os municípios

$\mathrm{t}=$ representa os anos

A normalidade dos dados é assumida pela Teoria do Limite Central. A inspeção gráfica dos resíduos padronizados versus os valores previstos indicou ausência de hoterocedasticidade. Para testar a suposição, quanto à ausência de multicolinearidade, nos modelos estimados, foi utilizada a estatística VIF (Variance Inflation Factor). O procedimento empregado foi especificar uma regressão pelo método POLS (Pooled Ordinary Least Squared) e calcular a estatística VIF. Os resultados evidenciaram a ausência de multicolinearidade, visto que o VIF, de todas as variáveis independentes, nos modelos estimados, ficou abaixo de dez.

A presente pesquisa emprega os níveis de significância de $0,1 \%, 1 \%$ e $5 \%$. As amostradas da pesquisa constam do Quadro 2 e englobam os anos de 2001 a 2012.

Quadro 2: Amostras analisadas na pesquisa

\begin{tabular}{|c|c|c|c|c|c|c|}
\hline \multicolumn{1}{|c|}{ EPD } & Todos & Norte & Nordeste & Sudeste & Sul & Centro-Oeste \\
\hline Amostra inicial & 14.039 & 889 & 2.414 & 4.299 & 4.936 & 1.501 \\
\hline (-) Observações retiradas & $(2.261)$ & $(199)$ & $(394)$ & $(571)$ & $(793)$ & $(304)$ \\
\hline Amostra analisada & 11.778 & 690 & 2.020 & 3.728 & 4.143 & 1.197 \\
\hline \hline
\end{tabular}

Fonte: Os autores (2018).

Os dados foram coletados junto ao Instituto Brasileiro de Geografia e Estatística (IBGE), a Secretaria do Tesouro Nacional (STN) da base de dados Finanças do Brasil (FINBRA), ao Tribunal Superior Eleitoral (TSE) e ao Atlas de Desenvolvimento Humano das Nações Unidas (PNUD). Os dados monetários foram deflacionados pelo IPCA/IBGE para dezembro de 1998 e transformados em valores per capita. 


\section{ANÁLISE DOS RESULTADOS}

\subsection{Análise descritivas dos investimentos públicos}

Esta seção descreve as principais características dos investimentos públicos realizados pelos municípios brasileiros com menos de cinco mil habitantes, entre 2001 e 2012. A composição percentual das despesas orçamentárias totais dos pequenos municípios, integrantes da amostra da pesquisa, é apresentada na Figura 1.

Figura 1 - Composição percentual média da despesa per capita total dos pequenos municípios, de 2001 a 2012

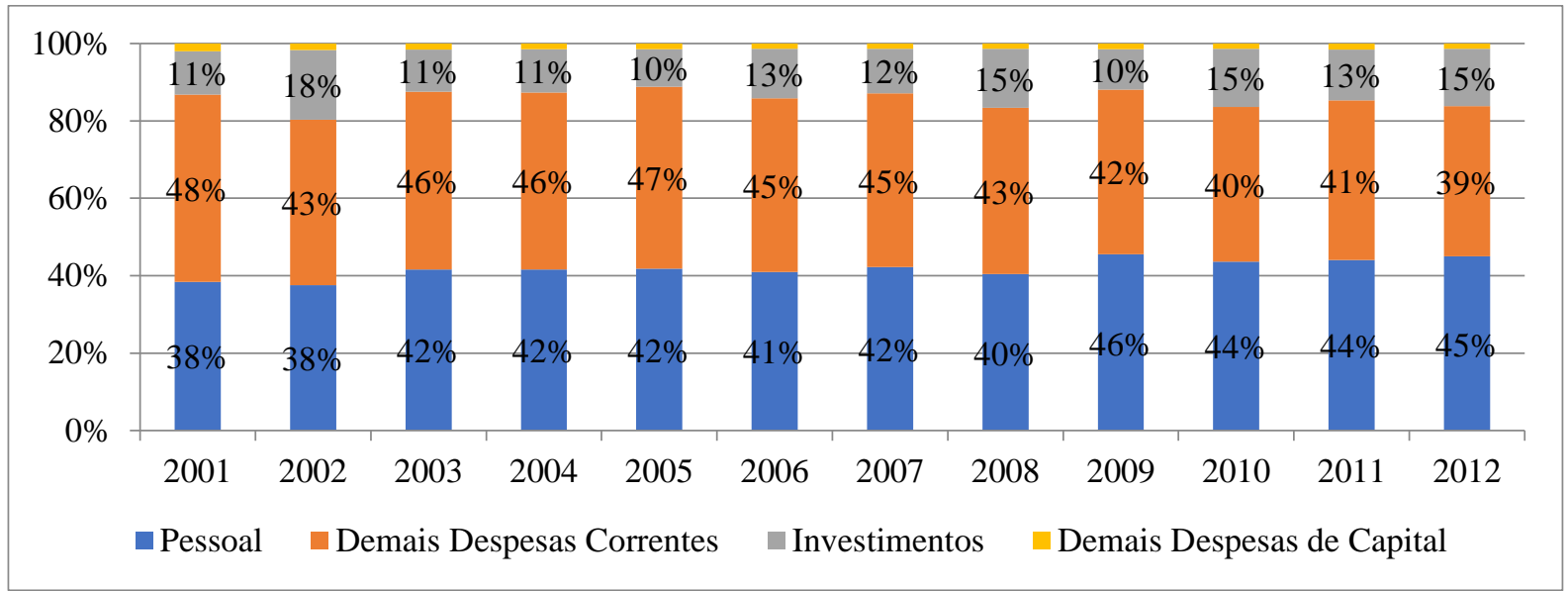

Fonte: MF/STN/FINBRA (2001 a 2012).

Os gastos municipais com pessoal e encargos sociais, por questões que regulamentam a forma de relação de trabalho entre os servidores municipais e os entes locais, especialmente a estabilidade no cargo dos funcionários efetivos, configura-se como uma importante natureza das despesas municipais. Razão pela qual os pequenos municípios registraram percentuais de gastos com pessoal e encargos sociais bastante homogêneos de 2001 a 2012. No início da série, 2001 e 2002, o percentual gasto com pessoal foi de 38\%; entre 2003 e 2008 a média dos gastos com pessoal representou em torno de $41 \%$ das despesas totais per capita, entre 2009 e 2012 o percentual médio das despesas com pessoal passou a ser de $45 \%$.

As demais despesas correntes englobam, além das despesas com juros, as destinadas à manutenção da estrutura municipal existente, como a aquisição de materiais de consumo (combustíveis, materiais odontológicos, hospitalares, de limpeza, de escritório, de construção, gêneros de alimentação etc.), aquisição de materiais para distribuição gratuita (como medicamentos), contração de serviços de terceiros (como serviços mecânicos, elétricos, hidráulicos, entre outros). Os dados evidenciaram que de 2001 a 2007 a média de gastos com essa natureza de despesa ficou em torno de $46 \%$ do total das despesas per capita, que de 2008 a 2012 a média passou a 42\%, e, ainda, que os anos finais da série contabilizaram os menores percentuais de gastos com essa natureza da despesa corrente.

Dentre as despesas de capital, as com investimentos públicos foram responsáveis por $12,8 \%$ das despesas totais per capita entre 2001 e 2012. O maior percentual aplicado em investimentos foi de $18 \%$, em 2002, seguido por 2008, com 16\%, e 2011 e 2012, ambos com $15 \%$. As demais despesas de capital, basicamente, resumiram-se às amortizações de contratos de empréstimos e apresentaram gastos em torno de $2 \%$ das despesas totais.

Na Figura 2 são evidenciadas as médias anuais de recursos aplicados pelos pequenos municípios em investimentos públicos, levando-se em consideração as cinco regiões brasileiras. A média per capita de recursos aplicados em investimentos públicos pelos pequenos municípios, que compuseram a amostra pesquisada, passou de $\mathrm{R} \$ 81$ a $\mathrm{R} \$ 211$, de 2001 a 2012, 
aumento de 160,5\%. Porém, os gastos não se elevaram linearmente, mas sim em anos específicos e de maneira mais constante nos últimos anos da série.

Figura 2 - Despesa per capita média em investimentos públicos dos pequenos municípios, por região - 2001 a 2012

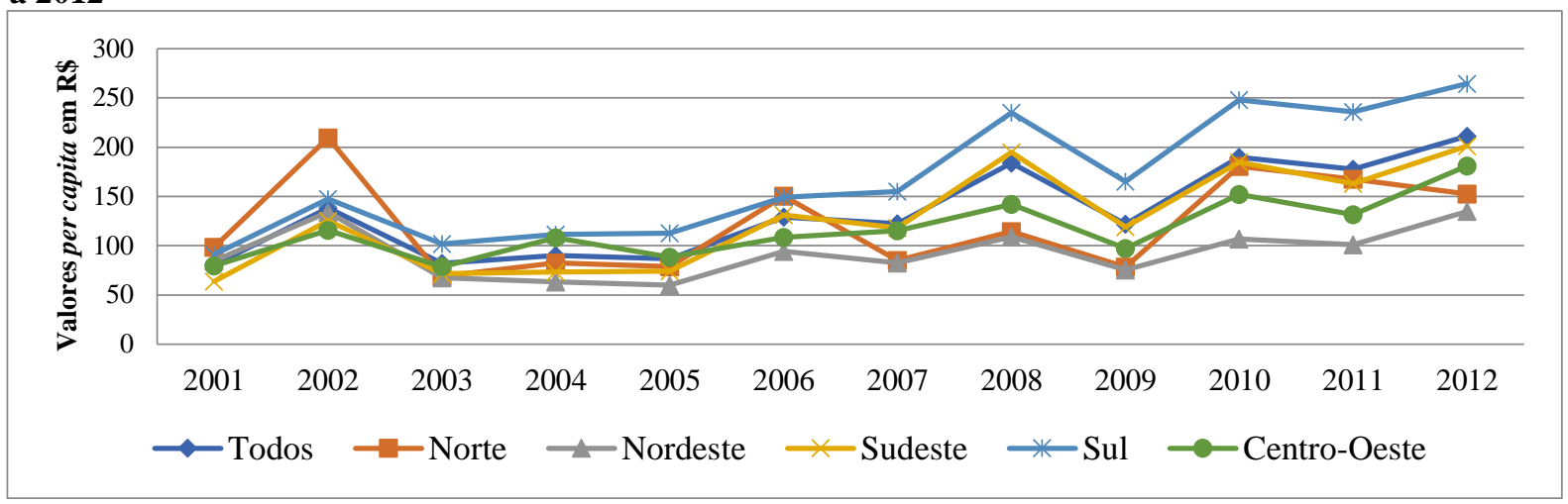

Fonte: MF/STN/FINBRA (2001 a 2012).

Valores deflacionados pelo IPCA/IBGE para dezembro/1998.

No primeiro ano da série, os pequenos municípios da região Norte aplicaram, em média, $\mathrm{R} \$ 98$ per capita, no último ano a média foi de $\mathrm{R} \$ 152$, acréscimo de 55,1\%. No Nordeste, evoluiu-se de R $\$ 85$ a R \$ 135, incremento de 58,8\%. No Sudeste houve alta de 214\%, passandose de R\$ 64 a R\$201. No Sul passou-se de R\$ 91 a R\$265, uma evolução de $191,2 \%$. No Centro-Oeste, passou-se de $\mathrm{R} \$ 80$ a $\mathrm{R} \$ 181$, alta de 126,2\%. Em outras palavras, os pequenos municípios de todas as regiões aumentaram suas aplicações em investimentos públicos em todos os anos a partir de 2004.

As médias per capita dos gastos com investimentos públicos e das receitas totais registradas pelos pequenos municípios pesquisados, entre 2001 e 2012, são evidenciadas na Figura 3.

Figura 3 - Médias per capita dos gastos com investimentos e das receitas totais dos pequenos municípios 2001 a 2012



Fonte: MF/STN/FINBRA (2001 a 2012).

Valores deflacionados pelo IPCA/IBGE para dezembro/1998.

Observa-se que a proporção de recursos aumentou acima da evolução das receitas totais. Estas passaram de $\mathrm{R} \$ 737$ para $\mathrm{R} \$ 1.629$, de 2001 a 2012, alta de $121 \%$, enquanto as despesas com investimentos públicos aumentaram $\mathrm{R} \$ 160,5 \%$, de $\mathrm{R} \$ 81$ a $\mathrm{R} \$ 211$. Porém, o percentual médio das receitas totais aplicadas em investimentos públicos ficou em torno de 11,5\%.

Em 2002 a média per capita aplicada em investimentos foi de R \$138, representando $16,3 \%$ da arrecadação total. No ano de 2006 os valores gastos foram de pouco mais de $\mathrm{R} \$ 129$, contra $\mathrm{R} \$ 1.100$ de receita total, ou 11,7\%. A média per capita aplicada em despesas com 
investimentos, em 2008, ficou em torno de $\mathrm{R} \$ 184$, ou 13,3\% do total arrecadado. Em 2010 as aplicações foram de $\mathrm{R} \$ 189,13,1 \%$ das receitas totais; em 2012, os gastos representaram pouco mais de $12,9 \%$ do total arrecadado, totalizando $\mathrm{R} \$ 211$.

As médias per capita das despesas com investimentos públicos e do total dispendidos pelos municípios brasileiros com menos de cinco mil habitantes, que integraram a amostra da pesquisa, entre 2001 e 2012 constam da Figura 4.

Figura 4 - Médias per capita das despesas com investimentos públicos e das despesas totais dos pequenos municípios - 2001 a 2012

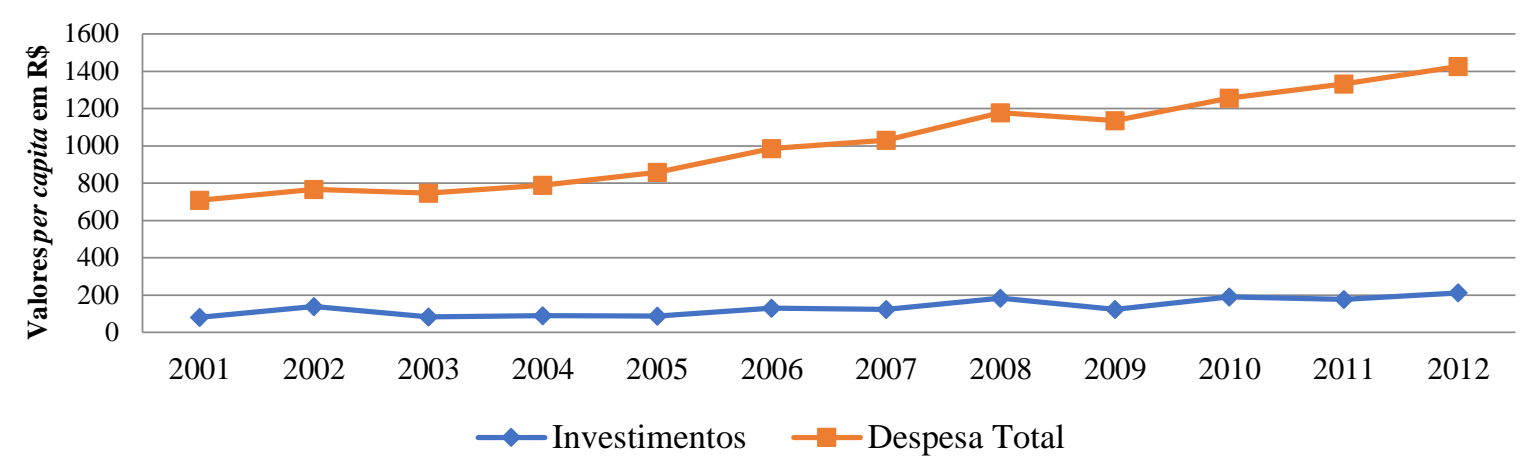

Fonte: MF/STN/FINBRA (2001 a 2012).

Valores deflacionados pelo IPCA/IBGE para dezembro/1998.

Em 2001 os gastos representaram 11,4\% das despesas totais. Em 2002 a média per capita foi de $\mathrm{R} \$ 138,18 \%$ das despesas totais. Em 2006 os valores gastos foram de $\mathrm{R} \$ 129$, ou $13,1 \%$ das despesas per capita médias do ano. Em 2008, teve-se R $\$ 184$ ou 15,6\% do total; em 2010, R\$ 189 ou $15 \%$ e, em 2012, R \$ 211 ou 14,8\% das despesas totais.

A comparação entre a arrecadação média per capita das receitas de capital e dos gastos com investimentos públicos dos pequenos municípios estudados, entre 2001 e 2012, é apresentada na Figura 5.

Figura 5 - Médias per capita das receitas de capital e dos gastos com investimentos públicos dos pequenos municípios - 2001 a 2012

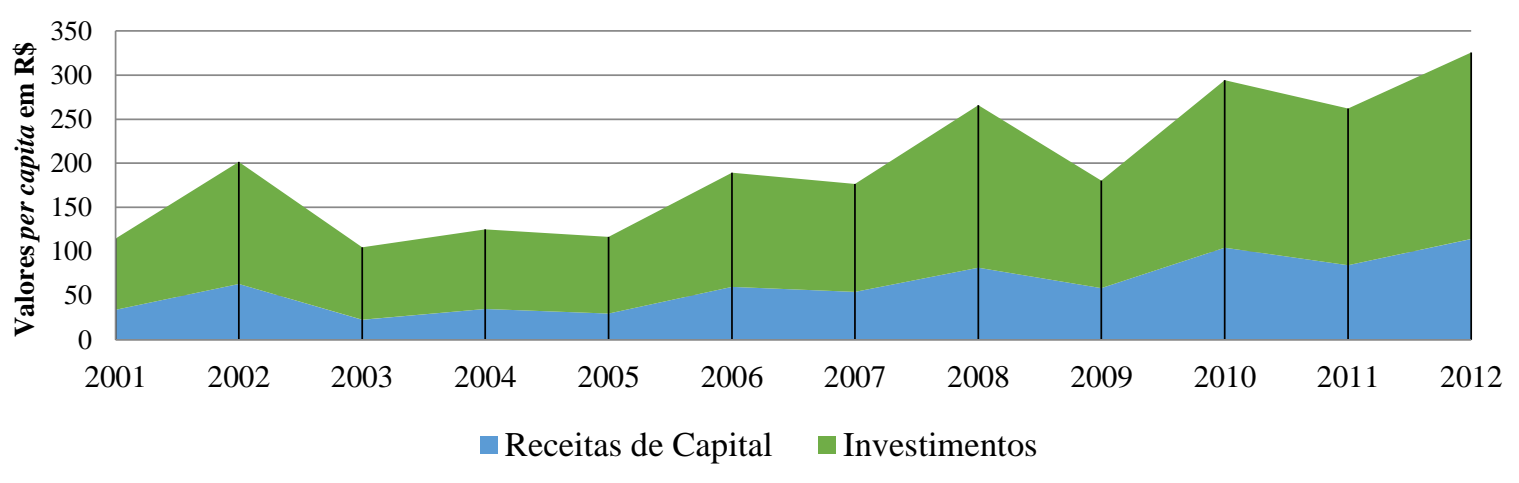

Fonte: MF/STN/FINBRA (2001 a 2012).

Valores deflacionados pelo IPCA/IBGE para dezembro/1998.

As receitas de capital, por sua natureza, devem ser aplicadas em despesas de capital (em especial, investimentos e inversões financeiras), ou seja, não podem custear despesas correntes (pessoal, juros e outras despesas correntes).

Entre 2001 e 2012, as receitas de capital custearam, em média, 44\% dos gastos com investimentos públicos. Em 2002, 2006, 2008, 2010 e 2012, tais receitas responderam, respectivamente, por $45,7 \%, 46,5 \%, 44,4 \%, 55,1 \%$ e $54 \%$ dos investimentos públicos 
realizados pelos pequenos municípios. Diante desses valores, os investimentos públicos realizados pelos pequenos municípios foram financiados, em grande medida, pela economia na execução do orçamento corrente, receitas correntes menos as despesas correntes, denominado superávit corrente orçamentário.

As despesas de capital realizadas pelos pequenos municípios amostrados, entre $2001 \mathrm{e}$ 2012, contabilizaram média per capita de $\mathrm{R} \$ 149$. Em 2001 essas despesas foram de R $\$ 94$ por habitante, passando a $\mathrm{R} \$ 230$ em 2012, alta de 144,6\%. As proporções anuais das despesas de capital que se referem a investimentos são evidenciadas na Figura 6.

Figura 6 - Proporção dos gastos com investimentos públicos em relação as despesas de capital dos pequenos municípios - 2001 a 2012

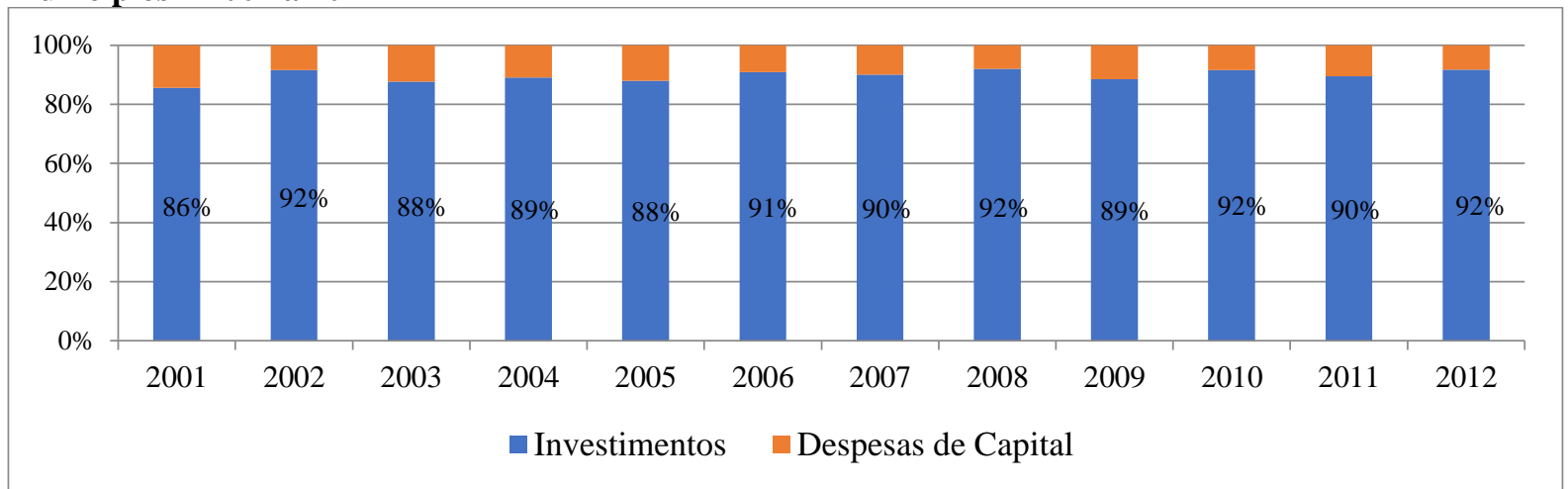

Fonte: MF/STN/FINBRA (2001 a 2012).

Os gastos com investimentos públicos representaram, em média, 89,7\% das despesas de capital. Nos últimos três períodos eleitorais (2008, 2010 e 2012), tanto federal-estadual como municipal, essa proporção foi de $92 \%$. Assim, as despesas de capital nos pequenos municípios, majoritariamente, são realizadas com a finalidade de adquirir ou construir um novo bem público.

\subsection{Análise de regressão}

Nesta seção, são identificadas as variáveis políticas que impactaram os investimentos públicos nos pequenos municípios e comparamos possíveis semelhanças e diferenças apresentadas por tais municípios, considerando-se as regiões a que estão vinculados. Os resultados são apresentados na Tabela1.

As eleições federais-estaduais foram estatisticamente significantes na estimação com os pequenos municípios da amostra e nas por regiões. O sinal foi positivo para todas as regressões, o que indica que em tais períodos eleitorais os gastos com investimentos públicos aumentaram em relação aos períodos em quem não ocorreram eleições.

Nos anos de eleições estaduais e federais, a elevação dos gastos com investimentos públicos, em média, foi de $\mathrm{R} \$ 35,41$ per capita na estimação com o conjunto total da amostra, em comparação aos anos sem eleições. Nas regiões o acréscimo foi de R $\$ 61,93$, no Norte, maior incremento médio entre as regiões, de $\mathrm{R} \$ 26,04$, no Nordeste, $\mathrm{R} \$ 39,10$, no Sudeste, $\mathrm{R} \$$ 34,52, no Sul e R \$28,06, no Centro-Oeste. As eleições municipais, exceto na região Norte, também se apresentaram significantes para os investimentos realizados pelos pequenos municípios e a relação registrada nas estimações foi positiva, evidenciando aumento dos gastos com investimentos em anos de eleições municipais.

A análise englobando os pequenos municípios da amostra indicou que o acréscimo nos gastos com investimentos públicos foi de $\mathrm{R} \$ 26,51$ per capita em anos de eleições municipais, quando comparados com os anos em que não se realização eleições locais. Entre as regiões, a 
alta ficou em $\mathrm{R} \$ 29,72$, no Sul, $R \$ 27,53$, no Sudeste, $R \$ 26,95$, no Centro-Oeste, $R \$ 23,47$, no Nordeste.

Tabela 1: Determinantes políticos dos gastos com investimentos públicos, entre 2001 a 2012, estimação geral e por regiões brasileiras - efeitos fixos

\begin{tabular}{|c|c|c|c|c|c|c|}
\hline \multirow{2}{*}{ Investimentos per capita } & \multicolumn{6}{|c|}{ Municípios com menos de 5 mil habitantes } \\
\hline & Todos & Norte & Nordeste & Sudeste & Sul & Centro-Oeste \\
\hline \multirow[t]{2}{*}{ Eleições Estaduais/Federais } & $35,41 * * *$ & $61,93 * * *$ & $26,04 * * *$ & $39,10 * * *$ & $34,52 * * *$ & $28,06 * * *$ \\
\hline & $(23,86)$ & $(9,58)$ & $(8,78)$ & $(15,55)$ & $(12,35)$ & $(5,82)$ \\
\hline \multirow[t]{2}{*}{ Eleições Municipais } & $26,51 * * *$ & 11,89 & $23,47 * * *$ & $27,53 * * *$ & $29,72 * * *$ & $26,95 * * *$ \\
\hline & $(17,25)$ & $(1,72)$ & $(7,41)$ & $(10,55)$ & $(10,55)$ & $(5,50)$ \\
\hline \multirow[t]{2}{*}{ Ideologia de Centro } & $13,40 * * *$ & 22,24 & 5,92 & 3,61 & $19,49 * *$ & 8,61 \\
\hline & $(3,89)$ & $(1,33)$ & $(0,86)$ & $(0,58)$ & $(3,17)$ & $(0,55)$ \\
\hline \multirow[t]{2}{*}{ Ideologia de Direita } & $8,36^{*}$ & 20,61 & 3,52 & $-1,71$ & $12,87^{*}$ & 7,03 \\
\hline & $(2,47)$ & $(1,26)$ & $(0,52)$ & $(-0,29)$ & $(2,17)$ & $(0,45)$ \\
\hline \multirow[t]{2}{*}{ Relação Partidária Presidente } & $10,31 *$ & 19,27 & 6,12 & $14,93^{*}$ & 3,85 & 1,87 \\
\hline & $(2,34)$ & $(0,85)$ & $(0,54)$ & $(2,10)$ & $(0,51)$ & $(0,13)$ \\
\hline \multirow[t]{2}{*}{ Coligação Direta Presidente } & $5,49 *$ & $-5,71$ & 5,00 & 1,73 & $12,16 * *$ & 9,58 \\
\hline & $(2,46)$ & $(-0,61)$ & $(0,98)$ & $(0,45)$ & $(3,00)$ & $(1,58)$ \\
\hline \multirow[t]{2}{*}{ Coligação Indireta Presidente } & $12,13 * * *$ & 14,19 & $15,11 * * *$ & 3,91 & $18,65 * * *$ & $12,02 *$ \\
\hline & $(7,23)$ & $(1,95)$ & $(4,38)$ & $(1,43)$ & $(5,56)$ & $(2,56)$ \\
\hline \multirow[t]{2}{*}{ Relação Partidária Governador } & $-8,25 * *$ & $-3,58$ & $-10,16$ & $-4,29$ & $-15,16^{* * *}$ & 5,25 \\
\hline & $(-3,29)$ & $(-0,36)$ & $(-1,75)$ & $(-0,88)$ & $(-3,51)$ & $(0,74)$ \\
\hline \multirow[t]{2}{*}{ Coligação Direta Governador } & 2,88 & $-12,16$ & 3,13 & 4,26 & 5,10 & 0,24 \\
\hline & $(1,48)$ & $(-1,53)$ & $(0,74)$ & $(1,18)$ & $(1,54)$ & $(0,04)$ \\
\hline \multirow[t]{2}{*}{ Coligação Indireta Governador } & $7,88 * * *$ & $20,75^{* *}$ & $8,76^{*}$ & $9,73 * *$ & 4,29 & $-2,22$ \\
\hline & $(4,39)$ & $(2,80)$ & $(2,45)$ & $(3,20)$ & $(1,19)$ & $(-0,42)$ \\
\hline \multirow[t]{2}{*}{ NEP Executivo } & $-4,54$ & $-21,92$ & $-9,05$ & $-5,71$ & $-0,76$ & 2,99 \\
\hline & $(-1,62)$ & $(-1,82)$ & $(-1,30)$ & $(-1,35)$ & $(-0,13)$ & $(0,40)$ \\
\hline \multirow[t]{2}{*}{ NEP Legislativo } & $-2,13 *$ & $-3,91$ & 0,63 & $-1,40$ & $-1,59$ & 2,50 \\
\hline & $(-2,24)$ & $(-1,18)$ & $(0,32)$ & $(-0,91)$ & $(-0,73)$ & $(0,96)$ \\
\hline \multirow[t]{2}{*}{ População Total (Log. Natural) } & $-9,60 * *$ & $-1,65$ & $-13,15^{*}$ & 2,70 & $-40,44$ & $-27,69$ \\
\hline & $(-2,68)$ & $(-0,13)$ & $(-2,55)$ & $(0,49)$ & $(-1,92)$ & $(-0,89)$ \\
\hline \multirow[t]{2}{*}{ População Jovem (\%) } & $-398,95 * * *$ & $-106,42$ & 18,69 & $-586,33 * * *$ & $-633,18 * * *$ & $-42,49$ \\
\hline & $(-12,65)$ & $(-0,80)$ & $(0,29)$ & $(-9,29)$ & $(-9,21)$ & $(-0,39)$ \\
\hline \multirow[t]{2}{*}{ População Idosa (\%) } & $1184,81 * * *$ & $1381,31 * *$ & 351,66 & $1147,42 * * *$ & $1128,09 * * *$ & $542,75^{*}$ \\
\hline & $(18,04)$ & $(3,46)$ & $(1,92)$ & $(9,56)$ & $(8,74)$ & $(2,36)$ \\
\hline \multirow[t]{2}{*}{ PIB municipal per capita } & $0,007 * * *$ & 0,005 & 0,009 & $0,006 * * *$ & $0,007 * * *$ & $0,007 * *$ \\
\hline & $(9,92)$ & $(1,38)$ & $(1,76)$ & $(4,67)$ & $(6,56)$ & $(3,16)$ \\
\hline \multirow[t]{2}{*}{ Constante } & $94,13 * * *$ & 30,69 & $120,67 * *$ & 43,35 & $384,24 *$ & 182,22 \\
\hline & $(3,53)$ & $(0,37)$ & $(3,44)$ & $(1,12)$ & $(2,12)$ & $(0,66)$ \\
\hline $\mathrm{N}^{\circ}$ Observações & 11.778 & 690 & 2.020 & 3.728 & 4.143 & 1.197 \\
\hline $\mathrm{R}^{2}$ & 0,2091 & 0,2098 & 0,1159 & 0,2200 & 0,2971 & 0,1186 \\
\hline Estatística F & 148,34 & 8,20 & 12,10 & 50,21 & 85,31 & 7,26 \\
\hline Prob $>F$ & 0,000 & 0,000 & 0,000 & 0,000 & 0,000 & 0,000 \\
\hline Teste de Chow & 4,63 & 2,18 & 3,86 & 3,98 & 4,68 & 4,78 \\
\hline Prob $>$ F & 0,000 & 0,000 & 0,000 & 0,000 & 0,000 & 0,000 \\
\hline Teste de Hausman & 381,78 & 40,31 & 22,87 & 175,07 & 167,08 & 24,92 \\
\hline Prob $>\mathrm{Chi}^{2}$ & 0,000 & 0,000 & 0,087 & 0,000 & 0,000 & 0,051 \\
\hline
\end{tabular}

Fonte: O autor (2018).

Nota: Números entre parênteses são estatísticas robustas ( $t$-statistics) com base no erro-padrão ajustado.

Todas as estimações foram realizadas pelo método de efeitos fixos.

Significância: $0,1 \% * * * ; 1 \% * * ; 5 \% *$

Portanto, tanto as eleições federais/estaduais como as municipais apresentaram significância estatística e sinal positivo em todas as regressões. Diante disso, pode-se afirmar que os gastos com investimentos públicos nos pequenos municípios brasileiros, entre os anos de 2001 e 2012, foram influenciados positivamente pelos períodos eleitorais, ou seja, 
aumentaram nos anos eleitorais quando comparados com aqueles em que não ocorreram eleições. Isso confirma a Hipótese 1, seguindo os resultados de Drazen e Eslava (2005); Sakurai e Gremaud (2007); Veiga e Veiga (2007); Rodrigues (2010), Leite (2010) e Videira e Mattos (2011).

Por sua vez, as variáveis indicativas da ideologia partidária se mostraram significantes nas análises com a amostra total dos pequenos municípios e os da região Sul. Em ambos os casos, os partidos ideologicamente classificados como de centro e de direita aplicaram mais recursos em investimentos públicos que os de esquerda, devido ao sinal positivo registrado.

$\mathrm{Na}$ estimação com a amostra geral, os partidos de centro destinaram em média $\mathrm{R} \$ 13,40$ per capita a mais que os de esquerda e os de direita $\mathrm{R} \$ 8,36$. No Sul os de centro aplicaram $\mathrm{R} \$$ 19,49 e os de direita $\mathrm{R} \$ 12,87$ por habitante em investimentos, evidenciando, também, aplicações em investimentos locais superiores os partidos de esquerda. Nas demais regiões, a ideologia partidária não se mostrou relevante.

A respeito das possíveis diferenças, quanto aos gastos com investimentos públicos entre as ideologias partidárias, a hipótese é a de que: Gestões municipais realizadas por partidos de esquerda tendem a destinar maior volume de recursos em gastos com investimentos públicos do que as de partidos de centro e de direita (Hipótese 2).

Os resultados, em relação ao conjunto dos pequenos municípios da amostra, evidenciaram que as gestões locais que foram realizadas partidos políticos com ideologias de centro e de direita, no período de 2001 a 2012, aplicaram mais recursos em investimentos públicos que aquelas em que gestão foi de partidos ideologicamente classificados como de esquerda. Nas análises por regiões, somente no Sul a ideologia foi estatisticamente significante e, também, indicaram que os partidos de centro e de direita destinaram mais recursos para os investimentos locais que os de esquerda.

Assim, refuta-se a Hipótese 2, de que nos pequenos municípios brasileiros os partidos de esquerda privilegiariam os gastos com investimentos públicos, quando comparados com os partidos de centro e de esquerda. Também, não foi possível confirmar a hipótese nas análises regionais, devido à baixa significância estatística apresentada.

Esses resultados são contrários aos achados de Veiga e Veiga (2007), em estudo com os municípios portugueses, no qual os governantes de esquerda tendem a aplicar mais recursos em investimentos locais. E convergem com Rodrigues (2010), em relação às análises por regiões, visto que as concepções ideológicas dos governantes dos pequenos municípios não se mostraram um fator de diferenciação no que se refere aos gastos com investimentos públicos locais.

A relação partidária do Prefeito com o Presidente se mostrou significante apenas para a amostra total dos pequenos municípios e, na região Sudeste, com sinal positivo. Assim, quando esse alinhamento político se concretizou, indicou aumento per capita sobre os investimentos públicos na ordem de $\mathrm{R} \$ 10,31$ para o conjunto dos pequenos municípios analisado e de $\mathrm{R} \$$ 14,93 para os do Sudeste.

A coligação direta entre o Prefeito e o Presidente da república foi estatisticamente significante e positiva na estimação com a amostra total e na da região Sul, com acréscimo per capita sobre os investimentos públicos de $\mathrm{R} \$ 5,49$ e de $\mathrm{R} \$ 12,16$, respectivamente.

A coligação indireta entre o Prefeito e o Presidente (quando pelo menos um dos partidos da coligação que elegeu o Presidente esteve presente na coligação que elegeu o Prefeito) foi a variável mais significativa entre as que trataram das relações políticas dos pequenos municípios e governo federal. Não apresentou significância nas regiões Norte e Sudeste. Com isso, quando esse alinhamento ocorreu, contribuiu para aumentar os gastos per capita com investimentos municipais, em $\mathrm{R} \$ 12,13$ na estimação nacional, $\mathrm{R} \$ 15,11$ no Nordeste, $\mathrm{R} \$ 18,65$ no Sul, e $\mathrm{R} \$$ 12,02 no Centro-Oeste. 
A interação partidária entre o Prefeito e o Governador do seu respectivo estado sobre os investimentos públicos foi significante, nos modelos envolvendo os pequenos municípios pertencentes à amostra total e os da região Sul, porém, com sinal negativo. Diante disso, quando o gestor local e o estadual eram do mesmo partido, os investimentos municipais apresentaram retração per capita na proporção de $\mathrm{R} \$ 8,25$ na amostra total e de $\mathrm{R} \$ 15,16$ na região Sul.

A coligação direta entre o Prefeito e o Governador do estado, quando o partido do governador compôs a coligação que elegeu o prefeito, não se mostrou estatisticamente significante com os investimentos públicos dos pequenos municípios brasileiros analisados.

A relação partidária indireta entre o Prefeito e o Governador, apresentou significância estatística na análise com os pequenos municípios da amostra e nas regiões Norte, Nordeste e Sudeste e o sinal registrado foi positivo. Com isso, os investimentos públicos sofreram um incremento médio per capita de $\mathrm{R} \$ 7,88, \mathrm{R} \$ 20,75, \mathrm{R} \$ 8,76$ e $\mathrm{R} \$ 9,73$, respectivamente, quando pelo menos um dos partidos da coligação do Governador esteve presente na coligação que elegeu o Prefeito.

Quanto aos efeitos dos alinhamentos políticos, direto ou indireto, entre o Prefeito e o Presidente e/ou com o Governador do estado, a hipótese enunciada foi de que: Os governos municipais alinhados politicamente com o governo federal e/ou estadual tendem a ter níveis maiores de gastos em investimentos públicos (Hipótese 3).

Quanto ao alinhamento político com o governo federal, os resultados ratificam a Hipótese 3, quando abordados os pequenos municípios da amostra, ou seja, estarem alinhados politicamente, direta ou indiretamente, com o governo federal, favorecem os investimentos públicos locais, entretanto, não é possível ratificar tal hipótese nas análises por regiões. Seguem-se os achados de Vieira e Arvate (2008), de que os municípios brasileiros, alinhados politicamente com o Presidente, apresentam maiores gastos com investimentos no âmbito local.

Quanto aos vínculos políticos entre os pequenos governos locais e o estadual, diante dos efeitos apresentados, não é possível confirmar a Hipótese 3: Os governos municipais alinhados politicamente com o governo federal e/ou estadual tendem a ter níveis maiores de gastos em investimentos. Sakurai e Gremaud (2007) também não encontraram significância da relação partidária direta entre os Prefeitos paulistanos e o Governador do estado.

Entretanto, cabe registrar os efeitos positivos da coligação indireta entre os pequenos entes locais e os governos estaduais sobre os investimentos públicos. Apesar de não serem unânimes, indicaram que os gastos aumentaram nas análises com todos os pequenos municípios e em três das cinco regiões. Isso corrobora com os achados de Videira e Mattos (2011), que registram influências sobre os investimentos locais, quando os governos locais mantiveram alinhamentos políticos com os estaduais por meio de coligações.

O Número Efetivo de Partidos do Executivo municipal não se mostrou estatisticamente significante com os investimentos municipais. Indicando que a competição política no âmbito do Executivo local não exerceu influência sobre os gastos com investimentos públicos. $\mathrm{O}$ Número Efetivo de Partidos do Legislativo municipal somente foi significante na estimação com os pequenos municípios da amostra e com sinal negativo, ou seja, quanto maior a disputa entre os partidos políticos nas eleições para a Câmara de Vereadores, menor o valor aplicado em investimentos públicos locais. A retração evidenciada foi de $\mathrm{R} \$ 2,13$ per capita para cada ponto de acréscimo no Número Efetivo de Partidos do Legislativo local.

No que diz respeito aos impactos da competição política, a hipótese testada foi de que: Quanto maior for o nível de competição política nas eleições municipais menor a tendência de que os pequenos municípios aumentem os gastos com investimentos públicos (Hipótese 4). Com base nos efeitos da competição política sobre os gastos com investimentos públicos, não há evidências para confirmar a Hipótese 4, visto que os indicadores utilizados mostraram baixa relevância estatística nas estimações realizadas, ou seja, a ameaça eleitoral não influenciou a 
aplicação de recursos em investimentos nos municípios brasileiros com menos de cinco mil habitantes.

A população total foi relevante na análise com o conjunto de pequenos municípios da amostra e na região Nordeste, porém, apresentou sinal negativo, distinto do esperado. Assim, quanto maior a população, menor o volume destinado aos investimentos públicos no conjunto de todos os pequenos municípios e na região Nordeste. Esse resultado difere do encontrado por Sakurai e Gremaud (2007), em estudo com os municípios paulistas.

A população jovem, quando estatisticamente significante, teve relação negativa com os gastos analisados, o que não era esperado. Diante disso, as despesas com investimentos públicos apresentaram redução per capita, na ordem de R \$ 586,33 no Sudeste e de R \$ 633,18 no Sul. $\mathrm{Na}$ estimação com os pequenos municípios da amostra essa relação foi de $\mathrm{R} \$ 398,95$. Esses resultados são semelhantes aos encontrados por Sakurai e Gremaud (2007) e contrariam os evidenciados em Veiga e Veiga (2007), em que, quanto maior a população jovem, maiores os gastos com investimentos públicos nos municípios portugueses.

A população idosa, entretanto, somente não foi estatisticamente significante na região Nordeste, nas demais apresentou relação positiva com os investimentos públicos, conforme esperado. Com isso, os gastos com investimentos públicos locais nos pequenos municípios apresentaram, em média, alta per capita de $\mathrm{R} \$ 1.184,81$ na estimação com a amostra total, de $\mathrm{R} \$ 1.381,31$ no Norte, de $\mathrm{R} \$ 1.147,42$ no Sudeste, de $\mathrm{R} \$ 1.128,09$ no Sul e de $\mathrm{R} \$ 542,75$ no Centro-Oeste. Em Sakurai e Gremaud (2007) e Veiga e Veiga (2007), a população idosa não foi significante para os investimentos públicos locais.

O PIB per capita municipal foi relevante estatisticamente para os investimentos públicos na estimação com a amostra total e nas regiões Sudeste, Sul e Centro-Oeste, com sinal positivo. Assim, à medida que o PIB municipal cresceu, o volume de gastos com investimentos locais nos pequenos municípios também aumentou. No geral, a proporção de incremento foi de aproximadamente $\mathrm{R} \$ 0,007$ para cada real per capita gerado de PIB municipal. Na região Sudeste, essa relação foi de $\mathrm{R} \$ 0,006$ e os pequenos municípios das regiões Sul e Centro-Oeste registraram aumento de $R \$ 0,007$. Os resultados diferem de Vieira e Arvate (2008), em que o PIB municipal não foi significante.

A capacidade explicativa dos modelos estimados é apresentada com intuito informativo, não comparativo. Na predição com todos os pequenos municípios, 20,91\% da variação dos investimentos públicos é explicada pela regressão estimada. O coeficiente de determinação da região Norte foi capaz de explicar 20,98\% da variação registrada nos gastos com investimentos públicos. No Nordeste, a explicação foi de $11,59 \%$, o Sudeste ficou em $22 \%$, o Sul em $29,71 \%$, e, no Centro-Oeste, em 11,86\%.

\section{CONCLUSÃO}

O objetivo da presente pesquisa foi analisar a influência de variáveis políticas sobre os gastos com investimentos públicos realizados pelos municípios brasileiros com menos de cinco mil habitantes, no período de 2001 a 2012.

Considerando que os gastos com investimentos públicos aumentaram nos períodos de eleições, tanto municipais como federais/estaduais, conclui-se que o ciclo político orçamentário é um fenômeno presente nos pequenos municípios brasileiros pesquisados. E que o tamanho populacional não é um fator de diferenciação, visto que os resultados evidenciados estão alinhados com outras pesquisas que não consideram o porte populacional em suas análises.

Entretanto, observa-se, que os gastos com investimentos públicos nos municípios com menos de cinco mil habitantes, no período de 2001 a 2012, contabilizaram maior impacto monetário nas eleições federais/estaduais, quando comparados com os das municipais. Concluise, como isso, que os investimentos públicos, nos pequenos municípios, tendem a aumentar mais, quando são realizadas eleições federais/estaduais. 
Em relação à ideologia partidária dos Prefeitos, os resultados, em relação ao conjunto dos pequenos municípios da amostra, evidenciaram que as ideologias de centro e de direita, no período de 2001 a 2012, aplicaram mais recursos em investimentos públicos que os governantes municipais de partidos ideologicamente classificados como de esquerda.

Os resultados quanto ao alinhamento político dos governos municipais com o governo federal e/ou estadual evidenciaram que, para os pequenos municípios da amostra, manter um vínculo político, direto ou indireto, como o governo federal favorece os gastos com investimentos público locais. Isso fica mais evidente considerando os resultados dos impactos dos períodos de eleições federais/estaduais sobre os investimentos locais.

Todavia, destaca-se que as relações entre os pequenos governos locais e o federal, estabelecidos por meio de coligações indiretas foram mais relevantes para aumentar os gastos com investimentos públicos. Isso indicou que fazer parte da base de apoio político do governo federal, mesmo que indiretamente, foi um dos aspectos que contribuíram para que os pequenos municípios brasileiros tivessem melhores condições financeiras para aumentarem seus gastos com investimentos públicos, quando comparados com os pequenos municípios que não contavam com esse tipo de apoio político.

As análises permitem concluir que os investimentos públicos nos pequenos municípios brasileiros foram influenciados pelos períodos eleitorais (tanto municipais como federais/estaduais) e, também, pelo alinhamento político entre os governos locais e o governo federal, em especial por meio das coligações indiretas.

Os resultados encontrados se limitam aos municípios brasileiros com menos de cinco mil habitantes e ao período de 2001 a 2012. Diante dos resultados apresentados, sugere-se a realização de outros estudos com esse mesmo grupo de municípios, porém avaliando outras áreas de gastos municipais (gastos agregados), como administração e planejamento, habitação, urbanismo e transporte, que possibilitariam ampliar o entendimento sobre as políticas públicas nesse âmbito, bem como, pesquisa que englobem municípios em outras faixas populacionais.

\section{REFERÊNCIAS}

ANDRADE, Nilton. A. Contabilidade pública na gestão municipal. 3. ed. São Paulo: Atlas, 2007.

ARRETCHE, Marta; RODDEN, Jonathan. Política distributiva na Federação: estratégias eleitorais, barganhas legislativas e coalizões de governo. Dados, v. 47, n. 3, p. 549-576, 2004.

ARVATE, Paulo R.; AVELINO, George; LUCINDA, Claúdio R. Existe influência da ideologia sobre o resultado fiscal dos estados brasileiros. Estudos Econômicos. Instituto de Pesquisas Econômicas, v. 38, n. 4, p. 789-814, 2008.

ARVATE, Paulo R.; VIEIRA, Fausto J. A. Eleições municipais : como interagem os prefeitos e as outras esferas de governo para alcançar maior sucesso nas urnas. Encontro Nacional de Economia. Anais eletrônicos ... XXVI ANPEC: Encontro Nacional de Economia. Salvador. Disponível em: <http://www.anpec.org.br/encontro2008/artigos/200807211138360-.pdf>.

BRENDER, Adi; DRAZEN, Allan Political budget cycles in new versus established democracies. National Bureau of Economic Research - NBER. Working Paper $n^{\circ} 10539$. Cambridge, Jun., 2004. Disponível em: http://www.nber.org/papers/w10539.pdf. Acesso em: 15 mar. 2018

BEZERRA, Marcos O. Políticos, representação política e recursos públicos. Horizontes Antropológicos, v. 7, n. 15, p. 181-207, 2001. 
INVESTIMENTOS PÚBLICOS E FATORES POLÍTICOS NOS PEQUENOS MUNICÍPIOS BRASILEIROS: O QUE É RELEVANTE?

BITTENCOURT, Jeferson L. Evidências de ciclo político na economia brasileira: um teste para a execução orçamentária dos governos estaduais-1983/2000. 2002. 142 f. Dissertação (Mestrado em Economia) - Programa de Pós-Graduação em Economia. Universidade Federal do Rio Grande do Sul, Faculdade de Ciências Econômicas . 2002.

BORGES, André. Federalismo, dinâmica eleitoral e políticas públicas no Brasil: uma tipologia e algumas hipóteses. Sociologias, v. 12, n. 24, p. 120-157, ago. 2010.

BRASIL. Ministério da Fazenda/ Secretaria do Tesouro Nacional MF/STN. Consolidação das Contas Públicas: Séries Temporais 2000 a 2012.

\section{MF/STN/FINBRA. Finanças do Brasil - FINBRA, 2001 a 2012.}

CAVALCANTE, Pedro. A competição eleitoral gera governos mais eficientes? Um estudo comparado das prefeituras no Brasil. Revista de Administração Pública, v. 47, n. 6, p. 1569-1591, dez. 2013.

CAVALCANTE, Pedro L. C. A política faz diferença? Uma análise comparada dos determinantes políticos do desempenho dos governos municipais no Brasil. 2012. $230 \mathrm{f}$. Tese (Doutorado em Ciência Política) - Instituto de Ciência Política, Universidade de Brasília, 2012. Disponível em: http://hdl.handle.net/10482/10612. Acesso em: 16 jan. 2018.

CHHIBBER, Pradeep K..; NOORUDDIN, Irfan. Do Party Systems Count? Comparative Political Studies, v. 37, n. 2, p. 152-187, mar., 2004.

COÊLHO, Denílson. B. Competição política e a nova agenda social: por que os partidos políticos de esquerda e direita difundiram programas de transferência de renda no Brasil? Anais eletrônicos... $13^{\circ}$ Congresso BIEN (Basic Income Earth Network). São Paulo, Brasil, de 30/06 a 02/07 de 2010. Disponível em: http://www.sinteseeventos.com.br/bien/pt/papers/ denilsonbandeiracoelhoCompeticaopoliticaeanovaagendasocial.pdf. Acesso em: 25 abr. 2018.

COPPEDGE, Michael. A classification of Latin American political parties.Working Paper, $\mathrm{n}^{\circ}$ 244. Notre Dame: The Helen Kellogg Institute for International Studies. Nov., 1997. Disponível em: https://kellogg.nd.edu/publications/workingpapers/WPS/244.pdf.Acesso em: 20 mar. 2018.

COSSIO, Fernando A. B. O comportamento fiscal dos estados brasileiros e seus determinantes políticos. Revista Economia, v. 2, n. 1, p. 207-258, 2001.

DRAZEN, Allan; ESLAVA, Marcela. Electoral manipulation via expenditure composition: theory and evidence. National Bureau of Economic Research - NBER. Working Paper $n^{\circ}$ 11085. Cambridge, Jan., 2005. Disponível em: http://www.nber.org/papers/w11085.pdf. Acesso em: 15 mar. 2018.

FÁVERO, Luiz P. et al. Análise de dados: modelagem multivariada para tomada de decisões. Rio de Janeiro: Elsevier, 2009.

FERNANDES, Luis. Muito barulho por nada? O realinhamento político-ideológico nas eleições de 1994. Dados - Revista de Ciências Sociais. Rio de Janeiro, v. 38, n. 1, pp. 107144, 1995.

FERREIRA, Ivan F. S.; BUGARIN, Maurício S. Transferências voluntárias e ciclo político- 
orçamentário no federalismo fiscal brasileiro. Revista Brasileira de Economia, v. 61, n. 3, p. 271-300, set. 2007.

GUJARATI, Damodar. N.; PORTER, Dawn. C. Econometria básica. 5. ed. Porto Alegre: McGraw Hill e Bookman, 2011.

KOHAMA, Hélio. Contabilidade pública: teoria e prática. 10. ed. São Paulo: Atlas, 2008.

LEITE, Adailton A. B. Descentralização, responsabilização e (des)controle: determinantes e impactos da corrupção e má gestão dos recursos federais nos municípios brasileiro. 2010. 247 f. Tese (Doutorado em Ciência Política) - Centro de Filosofia e Ciências Humanas Departamento de Ciência Política, Universidade Federal de Pernambuco, Recife, 2010.

MAINWARING, Scott; POWER, Timothy; MENEGUELLO, Rachel. Partidos conservadores no Brasil contemporâneo: quais são, o que defendem, quais são suas bases. São Paulo: Paz e Terra, 2000.

MATIAS-PEREIRA, José. Curso de administração pública: foco nas instituições e ações governamentais. São Paulo: Atlas, 2008.

NAKAGUMA, Marcos Y.; BENDER, Siegfried. Ciclos políticos e resultados eleitorais: um estudo sobre o comportamento do eleitor brasileiro. Revista Brasileira de Economia, v. 64, n. 1, p. 3-24, 2010.

NORDHAUS, William D. The Political Business Cycle. The Review of Economic Studies, v. 42, n. 2, p. 169-190, 1975.

OLIVEIRA, Kleber V.; CARVALHO, Freferico A. A. A Contabilidade Governamental e o calendário eleitoral: uma análise empírica sobre um painel de municípios do Rio De Janeiro no período 1998 - 2006. Revista de Contabilidade e Organizações, v. 3, n. 5, p. 121-141, 2009.

ORAIR, Rodrigo O.; GOUVÊA, Raphael R.; LEAL, Ésio M. Ciclos políticos eleitorais e investimentos das administrações públicas no Brasil Brasília. Instituo de Pesquisa Econômica - IPEA, , 2014. Disponível em: <http://www.ipea.gov.br/portal/images /stories/PDFs/TDs/td_1999.pdf>. Acesso em: 20 fev. 2017

PETTERSSON-LIDBOM, Per. A Test of the Rational Electoral-Cycle Hypothesis. Research Papers in Economics, v. 16, p. 1-26, 2003.

QUEIROZ, Dimas B. Composição dos gastos públicos e resultados eleitorais: um estudo nos municípios brasileiros. $132 \mathrm{f}$. Tese (Doutorado em Ciências Contábeis) - Universidade Federal do Rio Grande do Norte, Natal, 2015.

REIS, Diego Araujo; SANTANA, José Ricardo. Os efeitos da aplicação dos royalties petrolíferos sobre os investimentos públicos nos municípios brasileiros. Revista de Administração Pública-RAP, v. 49, n. 1, p. 1-27, 2015.

RODRIGUES, Gilmar. Democracia e partidos políticos: os gastos públicos municipais como instrumento de análise político-ideológica. In: HOCHMAN, Gilberto; ARRETCHE, Marta; MARQUES, Eduardo (Eds.). Políticas Públicas no Brasil. Rio de Janeiro: Fiocruz, 2007. 
INVESTIMENTOS PÚBLICOS E FATORES POLÍTICOS NOS PEQUENOS MUNICÍPIOS BRASILEIROS: O QUE É RELEVANTE?

RODRIGUES, Gilmar. Partidos políticos e gastos públicos em santa catarina: a influência das ideologias partidárias nas decisões de investimentos. 2010. 263f. Tese (Doutorado em Sociologia Política) - Programa de Pós-Graduação em Sociologia Política, Universidade Federal de Santa Catarina, Florianópolis, 2010.

RODRIGUES, Leôncio M. Partidos, ideologia e composição social. Revista Brasileira de Ciências Sociais - RBCS. São Paulo, v. 17, n. 48, pp. 31-47, Fev., 2002.

ROGOFF, Kenneth; SIBERT, Anne. Elections and macroeconomic policy cycles. The Review of Economic Studies, v. 55, n. 1, p. 1-16, jan. 1988.

ROGOFF, Kenneth. Equilibrium political budget cycles. The American Economic Review. v. 80, n. 1, pp. 21-36, March, 1990. Disponível em: http://scholar.harvard.edu/files/rogoff /files/51_aer90.pdf. Acesso em: 20 fev. 2017.

SAKURAI, Sérgio N. Ciclos políticos nas funções orçamentárias dos municípios brasileiros: uma análise para o período 1990 - 2005 via dados em painel. Estudos Econômicos (São Paulo), v. 39, n. 1, p. 39-58, mar. 2009.

SAKURAI, Sérgio N.; GREMAUD, Amaury P. Political business cycles: evidências empíricas para os municípios paulistas (1989 - 2001). Economia Aplicada, v. 11, n. 1, p. $27-$ 54, mar. 2007.

SÁTYRO, Natália G. D. Política e instituições e a dinâmica das políticas sociais nos estados brasileiros: uma análise após a redemocratização. 2008. 178 f. Tese (Doutorado em Ciência Política) - Instituto Universitário de Pesquisas do Rio de Janeiros (IUPERJ), Universidade Estadual do Rio de Janeiro, Rio de Janeiro, 2008.

SHI, Min; SVENSSON, Jakob. Political budget cycles: Do they differ across countries and why? Journal of Public Economics, v. 90, n. 8-9, p. 1367-1389, set. 2006.

SLOMSKI, Valmor. Manual de contabilidade pública: um enfoque na contabilidade municipal, de acordo com a Lei de Responsabilidade Fiscal. 2. ed. São Paulo: Atlas, 2006.

TAROUCO, Gabriela S.; MADEIRA, Rafael M. Partidos, programas e o debate sobre esquerda e direita no Brasil. Revista de Sociologia e Política, v. 21, n. 45, p. 149-165, 2013a.

TAROUCO, Gabriela S.; MADEIRA, Rafael M. Esquerda e direita no sistema partidário brasileiro : análise de conteúdo de documentos programáticos. Revista Debates, v. 5, n. 2, p. 93-114, 2013b.

VEIGA, Linda G.; VEIGA, Francisco J. Political business cycles at the municipal level. Public Choice, v. 131, n. 1-2, p. 45-64, 2007.

VIDEIRA, Raphael A.; MATTOS, Enlinson. Ciclos políticos eleitorais e a interação espacial de políticas fiscais entre os municípios brasileiros. Economia Aplicada. São Paulo, v.15, n. 2, pp. 259-286. Abr./Jun. 2011.

VIEIRA, Fausto J. A.; ARVATE, Paulo R. Eleições municipais: como interagem os prefeitos e as outras esferas de governo para alcançar maior sucesso nas urnas. 2008. In: Encontro Nacional de Economia, 36, Salvador. Anais... Salvador: ANPEC, 2008. Disponível em: 
http://www.anpec.org.br/encontro2008/artigos/200807211138360-.pdf. Acesso em: 20 jan. 2016.

ZUCCO JUNIOR, Cesar. Esquerda, direita e governo: a ideologia dos partidos políticos brasileiros. In: POWER, Timothy J.; ZUCCO, JUNIOR, Cesar. (Ed.). O Congresso por ele mesmo: autopercepções da classe política brasileira. Belo Horizonte: UFMG, 2011. p. 3760 . 